\title{
Historicidad de la salvación cristiana
}

\author{
IGNACIO ELLACURIA \\ Centro de Reflexión Teológica \\ San Salvador
}

El problema de la historicidad de la salvación cristiana sigue siendo uno de los problemas más graves de la comprensión y de la práclica de la re. Lo es en el ámbito de los países noratlánticos: l to es lambién en el ámbito de los paises oprimidos, ${ }^{2}$ y lo es finalmente en la preocupación del magisterio y disciplina de la Iglesia instilucional. ${ }^{3}$ Por historicidad de la salvación crisliana no se entiende siempre lo mismo. Una primera distinción podria hacerse entre aquellos que se preguntan por el carácler histórico de los hechos salvificos y aquellos que se preguntan por el carácter salvifico de los hechos históricos; los del primer grupo se interesan sobre lodo por fundamentar históricamente, por constatar objetivamente hechos fundamentales de la fe, desde la resurreccion de Jesús como el hecho más importante hasla los milagros o la serie de sucesos salvíficos del Antiguo Testamento; los del segundo grupo se interesan especialmente por ver que hechos históricos Iraen salvación y cuáles otros Iraen condenación, quć hechos hacen inás presente a Dios y cómo en ellos se actualiza y se hace eficaz esa presencia. No son dos perspectivas cxcluyenles; más aun, la segunda presupone la primera y accpla sin mayores reservas que los grandes hechos salvificos, reveladores y comunicadores de Dios, se han dado en la historia, por más que su justificación crítica no pueda alcanzar ni reducirse a las comprobaciones de la ciencia histórica.

Este articulo sc coloca, más bien, en la segunda de las perspeciivas y quiere repensar el problema ya clásico de cómo se relacionan enıre si lo que es la salvación cristiana, que pareceria ser lo formalmente definitcrio de la misión de la Iglesia y de los cristianos en tanto que cristianos y lo que es la liberación hisıórica, que pareceria ser lo formalmente definilorio de los estados, las clases sociales, los ciudadanos, los hombres en tanlo que hombres. Al retomar de nuevo el problema no se pretende calmar una preocupación puramente intelectual surgida del desasosiego que pucde nacer de una paradoja teórica. Más bien se pretende, en primer lugar, aclarar un punto lundamental para la comprensión de la fe y para la eficacia de la praxis cristiana, especialmente en el contexto de la situación del Tercer Mundo y más en particular de América 
Latina; en segundo lugar, responder a quienes quieren invalidar los esfuerzos que hacen los teólogos de la liberación por repensar la revelación entera y la vida de la lglesia en busca de la salvación-liberación de los pobres de la tierra, pero en busca también de una prolunda renovación del pensamiento, de la espiritualidad, de la pastoral y aun de la institucionalidad de la Iglesia universal.

Cada día se acepta más el que los teólogos de la liberación representan una nueva forma de hacer teologia de gran trascendencia para la vida de la Iglesia y para la comprensión y explicación de la le cristiana. Después de una primera etapa en la cual se desechó su importancia afirmando que su labor era más sociológica que teológica y que, en el inejor de los casos, trataban puntos que tenian que ver con la élica social, se reconoció más tarde que sus temas eran fundamentales para la teología y, aún más, que se trataba de una teologia total, capaz de desplazar a otras formas de teologia que se consideraban como las únicas clásicas y universales. Asi la Comisión teológica intermacional en su reunión de 1976 suponia que era objeto principal de la teología de la liberación la conexión entre salvación cristiana y promoción humana y que "esla unidad de conexión asi como la diferencia que señala la relación entre promoción humana y salvación cristiana, en su forma concreta, deberán ser objeto de búsquedas y de nuevos análisis; ello constituye, sin duda ninguna, una de las tareas principales de la toelogía actual." "4 Con ocasión de esa misma reunión, Urs von Balthasar terminaba sus observaciones críticas con estas palabras: "la teología de la liberación tiene su puesto específico en una teología del reino de Dios; es un aspecto en el conjunto de la teologia, y está exigiendo la actuación práctica de la lglesia para la debida configuración del mundo en orden a Cristo." 5 Pero ha sido más recientemente el cardenal Ratzinger quien ha subrayado especialmente el carácter universal de la teología de la liberación al reconocerle a) pretender ser "una nuova ermeneulica della fede cristiana, vale a dire come una nuova forma de comprensione e di realizazione del cristianesimo nella sua totalita, " 6 b) que en ella confluyen varias corrientes de pensaniento y ella influye a su vez en regiones que desbordan la geografia y la cultura de América Latina; c) que adquiere un carácter ecuménico, "una nuova universalitá per la quale la separazioni clasicche delle Chiese debbono perdere la loro importanza."?

Esta cuestión de la historicidad de la salvación cristiana, ya lo decíamos, no es exclusiva de la teologia de la liberación, pero en ésta cobra una importancia singular y unas caracteristicas especiales.

La importancia singular no estriba en que la "Icología de la liberación" sea formalmente una "teologia de lo politico." El libro de Clodovis Boff, excelente por tantos capítulos, puede causar una imagen distorsionada de lo que es la teologia de la liberación o puede conducirla a regionalizaciones teológicas que no son ni necesarias ni deseables. ${ }^{8}$ La teologia de la liberación no ha de entenderse como una teologia de lo político, sino como una teologia del reino de Dios, de modo que la distinción de objetos materiales entre una $T$ I que Iratara los temas clásicos de Dios, Cristo, Iglesia y una T 2 que tratara los temas más directamente humanos y/o políricos ${ }^{9}$ no es en si aceplable, aunque consideraciones secundarias puedan insinuar ocasionalmente separaciones metódicas; la 
teologia de la liberación, en efecto, trata primariamente de todo lo que atañe al reino de Dios, sólo que enfoca todos y cada uno de sus tópicos, aun los más elevados y aparentemente separados de la hisıoria, sin olvidar nunca. y rrecuentemente con atención muy especial, a su dimensión liberadora.

Las características especiales de la leología de la liberación tampoco fluyen de que su objeto primario fundamental sea lo politico ni siquiera la liberación entendida de modo integral. Fluyen más bien del 'lugar' crisciano y epistemológico en el cual el teólogo se sitúa, de su opción preferencial por los pobres y de su propósito de que las virtualiclades del reino de Dios se pongan al servicio de la salvación histórica del hombre, poniendo eso si esta salvalción en lá más estrecha relación posible con lo que es la salvación cristiana clel hombre $y$ del mundo.

El problenua permanente de la relación entre lo divino y lo humano cobra así una importangia nueva y, sobre 1odo, una perspectiva nueva. ¿Quć lienen que ver los esfuerzos humanos por una liberación histórica. incluso sociopolítica, con la inslauración del reino de Dios que predicó Jesús? ¿Qué tiene que ver el anuncio del reino de Dios y su realización con la liberación hictórica de las mayorías oprimidas? Tales cuestiones en su doble vertiente representan in problema fundamental de la praxis de la Iglesia de los pobres a la par que un problema esencial de la historia actual latinoamericana. No es primariamente una cuestión conceptual, sino que es una cuestión real, que necesilará el uso de conceptos para ser resuelta teóricamente, pero que no es primaria ni últimamente una cuestión puramente tcórica. En efecto, no es primariamente un problema de conjunción leórica de dos conceplos absiractos, une que se refiriera a la obra de Dios y otro que se refiriera a la obra del hombre. El partir de los conceptos y del supuesto más o menos explicito de que a conceptos adecuadamente distintos corresponden realidades diferentes, lleva a dificullades superfluas. Los conceptos adecuadamente discintos serian dos y a csos dos conceptos se les alribuiria el correlato de dos realidades adecuadamenle distintas. Dicho de otra forma, tras una larga elaboración intelectual, realizada a to largo de siglos, se ha llegado a la separación conceptual de lo que cn la experiencia biográfica y en la experienciá histórica aparece como unido: csa separación conceplual, no sólo se ha considerado cada vez como más cvidente, sino que se ha converlido en punto de parlida para regresar a una realidad, que ya no es vista primigeniamente en si misma, sino a través cle la 'verdad' atribuida al conceplo. Separado el conceplo de la praxis histórica real y puesto al servicio ideologizado de instancias que inslitucionalizan intereses no criticados reflejamente, no sólo no se resuelve el problema, sino que sc lo encubre. Y se encubre, no lanto porque el concepto sea abstracto, sino más bien porque no es histórico. Hay una universalidad conceptual a-histórica y hay una universalidad conceptual histórica o, si se prefiere, historizada. Aquella puede parecer más teórica y más universal, pero no es asi tanto porque encubre una historicidad que en su encubrimiento opera deformantemente. como porque desconoce la dimensión propia de universalidad de la realidad hisıórica, apropiadamente conceptualizada. Cuando no se reflexiona críticamente de qué praxis histórica determinada surgen las conceptuaciones y a qué praxis conducen, se está en trance de servir a una historia, que tal vez el concepto dice negar. 
De esta sospecha epistemológica, comprobada una y otra vez en la praxis histórica de la Iglesia en América Lalina, se deduce la posición de la teologia de la liberación ante el problema de la 'relación' entre los diversos momentos de una misma praxis de salvación. No se trala primariannente de un problema de conceptualización o de un problenta teórico que ha de resolverse para salvar la ortodoxia. Se trala, al menos primeramente, de un problema de praxis, la praxis de unos crislianos que han querido participar crisianimente en las luchas que el nueblo ha emprendido por su propia liberación. Estos cristianos urgidos por su fe y como realización objeliva de esa fe quieren ver una maxima coincidencia ente lo clue Dios quiere de los hombes y to que los hombres hacen. Han escuchado los clamores del pucblo, de mi pucblo ${ }^{10}$ como escribian los obispos del nordeste de Brasil, pueblo explotado, digno de mejor causa, sabedor muchas veces de su condición de hijos de Dios. Esıos creventes han visio que con frecuencia quienes se dicen cristianos son responsables de muchos de los males que se abaten sobre los más pobres al (iempo que los que se dicen no creyentes se han dedicado con verdad y hasla el sacrilicio lolal a la liberación de los más pobres y oprimidos. Ante csta terrible paradoja se preguntan cómo puede ser esto asi y qué lienen que hacer con su fe y con sus obras para que no se siga dando esle escándalo, que puede acabar con la fe, hoy lodavia tan vigorosa, de las mayorias populares.

Para acercarnos a la solución de este problema lan fundamental en la praxis eclesial y en la confesión y comprensión de la fe, vamos a apoyarnos en un concepto tradicional; el concepto de transcendencia. Sin entrar en discusiones previas sobre el concepto de transcendencia, podernos ver en él algo que permite notar una diferencia momentual estructural sin tener que aceptar una dualidad; algo que permile hablar de una unidad intrinseca sin por eso caer en una estricta identidad. Aunque en la última parte de este trabajo haremos algunas reflexiones sobre esta unidad sill separación y sin confusión, desde un principio damos por aceptado que no se dan dos historias, una historia de Dios y una historia de los hombres, una historia sagrada y una historia prolana. Más bien lo que se da es una sola realidad histórica en la cual interviene Dios y en la cual interviene el hombre, de modo que no se da la intervención de Dios sin que en ella se haga presenle de una u olra forma el hombre y no se da la intervención del hombre sin que en ella se haga presente de algún modo Dios. Lo que se necesita discernir es la distinta intervención de Dios y del hombre y el distinto modo de 'relación' en esas intervenciones. De distinıo tipo es la intervención y la presencia de Dios en la intervención del hombre cuando ésı se da en el ámbito del pecado y cuando se da en el ámbito del anti-pecado, de la gracia. Hay una omniprescencia de Dios en la historia clue, por definición, es sicmpre divina, aunque esa presencia puede lomar formas distintas que difícilmente pueden clasificarse en la división simplista de naturales y sobrenaturalcs.

El pensamiento cristiano padece en este punto de influjos filosóficos perniciosos, que no dan razón del modo como se presenta el problema en la historia de la revelación. Se identifica lo transcendente con lo separado y asi se supone que la transcendencia histórica es lo que está separado de la hisioria; iranscendente sería lo que está fuera o más allá de lo que se aprehende inme- 
dialamente como real, de modo que lo Iranscendenle seria sicmple de olro, lo distinto y separado, sea en el tiempo, sea ell el espacio, sea ell sul entidad. Pcro hay otro modo radicalmente distinto de entender la transcenclencia, que es más consonante con la forma como se presenta la realidad y la acción de Dios en el pensamiento biblico. Este modo consiste en ver la Iranscendencia como algo que transciende 'en' y no como algo que trausciende 'dc,' como algo que lísicamente impulsa a "más" pero no sacaudo "luera de;" como algo que lanza, pero al misıno tiempo retiene. En esta concepción, cuando se alcanza históricamente a Dios -y lo mismo vale decir cuando se alcamba personalmente a Dios-, no se abandona lo humano, no ue abandona la hichoria leal, vino que se ahonda en sus raices, se hace más presentc y clicaz lo gue eslaba va efectivamente presente. Puede separarse Dios de la historia, pero no puede separarse de Dios la historia. Y en la hisıoria la transcenclencia hay que verla más ell la relación necesidad-libertad que en la relación ausencia-presencia. Dios es transcendente, entre otras razones, no porque se ausente, sino porque se hace libremente presentc, unas veces de un modo y otras de o1ro, libre y scñorialmente elegidas, unas con una intensidad y otras con olra imensidad, segum sca su voluniad de aurodonación. Como veremos despues, aun en cl caso del pecado esımos en plena hisioria de la salvación: el pecado no hace desaparecer a Dios, sino que lo crucifica, lo cual puede parecer lo mismo, pero en realidad es abismalmente distinto. Será posible diviclir la historia en una historia de pecado y una historia de la gracia, pero esa división supone la uniclad real de la historia y la unidad real $\mathrm{e}$ indisoluble de Dios y del hombre cn ella, supone además que pecado y gracia están en estrechisima relación de tal modo que aquella puede delinirse desde ésta y ésta desde aquélla. ${ }^{1]}$

Pero no pretendemos hacer aqui una discusión filosófica sobre el problema de la transcendencia, aunque vamos a utilizar el conceplo para llenarlo de un contenido preciso a través de algunos ejemplos del Antiguo y del Nuevo Testamento. Más bien lo que aqui se busca es mostrar la unidad primigenia d: lo divino y de lo humano en la historia, una unidad can primigeniá que sólo Iras una larga rellexión ha podido la humanidad hacer separaciones y dislinciones, unas veces justificadas y otras no. La transcendencia de la que hablamos sc presenta como histórica y la historia se presenta a su ve como trans. cendente por más que resulte dificil encontrar los conceptos adecuados para mantener esıa indivisa unidad sin confusión.

Varios punıos esenciales de la fe cristiana podrian Iomarse como pauta esclarecedora. Ante todo. el misterio transcendente de la limanidad de lesús. Es en Jesuis, verdadero hombre y verdaclero Dios como sostienc la lis cristiana. donde mejor se realiza la unidad y donde mejor podria estudiarse esa unidad. No es cl camino que aqui se va a recorrer porque su estudio no puede mi siquiera ser apuntado en un trabajo como éste de reducidas dimensiones y prelensiones. Podria estudiarse también el mismo problema cu el caso de la lglesia con su historicidad evidente y palpable por un laclo y por otro con st caracter de misterio confesado por la fe; cs un caso de estudio que podría aportar pislas teóricas de primera importancia, ya que la historización del misterio de la Iglesia debidamente criticada dejaria sin fucrza muchos de los argumentos con que 
se ataca la historización de la fe propiciada por la teologia de la liberación. Podría estudiarse también el caso singular de los libros sagrados en los que, por un lado es tan evidente la acción del hombre como vehículo de la revelación y, por otro lado, es necesario admilir por la fe la presencia de la autoría de Dios.

Por razones prácticas en este trabajo se van a tomar como objeto de cstudio dos casos distintos de pretensiones más modestas con el objeto de mosirar lo que pudiera ser, por un lado, la trascendencia histórica veterotestamentaria $y$. por otro, la transcendencia histórica neotestamentaria. No es que se aceptc desde un principio que se trate de dos modos distintos de transcendencia divina en la historia, de los cuales el primero quedaría superado, cuando no anulado por el segundo. Cuando Von Balthasar afirma en relación con la leologia de la liberación que "lo religioso en Israel queda siempre político, y lo politico religioso, hasıa en la misma entraña de su esperanza escatológica" y en consecuencia añade "este monismo religion-polílica, que es esencialmente constilulivo para Israel, ha sido y sigue siendo para la Iglesia siempre y en todas sus formas (cesaropapismo, "cuius regio ...') del todo perjudicial," 2 está afírmando algo que desfigura el problema. La teologia de la liberación ha sido acusada con frecuencia de ser más veterotestamentaria que neotestamentaria en su preocupación histórico-política fundamental. Apariencias para ello se han dado. Pero no se superará la objeción abandonando la inspiración que se encuentra en los hechos históricus-salvíficos del Antiguo Testamento, sino iluminándolos con la luz del Nuevo Testamento, pero sin plantear el problema en términos de la edad de la gracia que deja atrás la edad de la ley. Querer sacar del Antiguo Testamento sólo lo que en él hay de espíritu religioso abandonan. do todo lo que en él hay de carne histórica y asimismo querer quedarse con lo que de espiritu hay en el Nuevo Testamento sin reparar en lo que hay en él de historicidad o limitar el sentido de ésta a puro apoyo de aqué, sería en ambos casos una mutilación. En ambos casos hay espiritu y carne. Dios e historia, tan inseparablemente unidos, que la desaparición de uno traería consigo la desfiguración, cuando no la destrucción, del otro.

Evidentemente no se va a estudiar a Tondo ni lo que es la Iranscendencia histórica veterolestamentaria ni la neotestamentaria; lampoco la relación cntre ambas. Bastará con apoyarse en algunos aspecios signficativos de las mismas para acercarse a una mayor claridad sobre el problema que nos ocupa; la transcendencia histórica cristiana que abarca aquellas dos perspectivas, pero también lo que el Espiritu ha ido creando y manifestando y que es menester descifrar como "signos de los tiempos."1.3

\section{La transcendencia histórica veterotestamentaria}

El punto elegido para este grave problema puede formularse asi: ¿quién sacó de Egipto al pueblo, Yahvé o Moisés? Esıa pregunla liene los siguientes presupuestos: 1) la salida de Egipło del pueblo de Israel es un hecho histórico o se presenta como un hecho histórico; 2) la salida de Egiplo es un hecho salvifico de transcendental importancia para cumplir el plan de Jahvé con su 
pueblo; 3) Moisés es un hombre que utiliza medios humanos y politicos para realizar ese hecho hislórico-salvifico; 4) lsrael no duda en creer, a pesar de la presencia comprobada de los hombres en la acción, que Yahvé es quien lo esı́a liberando.

Poco importa para nuestro propósito que se niegue la historicidad científica y critica de los hechos narrados en el Exodo, porque siempre cabria preguntarse, desde un punto de vista teológico, por qué la Iradición revelante se ha visto forzada a dar carne histórica a un contenido supuestamente no hislórico de revelación y de aulodonación de Dios. Aceptamos eso sí que en esa historia o en esa historificación sucedió, segin lo expresa tan explicitamente el autor inspirado, algo que debe aceplarse creyentemente como presencia y acción salvífica de Dios. El supuesto racionalista, no creyente, según el cual to que se cuenta en el Exodo es mera mitologia o mera ideologización, revestidas de ropaje histórico, exigiria otro tratamiento. Aqui se supone creyentemente que esa intervención de Dios es posible, que esa intervención es siempre libre y que esa intervención se dio o que, al menos, el autor sagrado la interpretó como dada. Pero insistimos, aunque no se diera lal como se narra, la narración misma en lo que pudiera llamarse su lógica interna revelante es suficiente punto de apoyo para mostrar lo que aqui pretendemos. Admitir aquí que entre el significante y el singificado se da una relación puramente extrínseca no hace justicia al texio ni a la intención y propósito del redacior.

Ciertamente entre los propios creyentes se discute cuál es el carácter histórico de la historia de la salvación o de los hechos salvíficos y en qué consiste su historicidad. ${ }^{14}$ Asi de Vaux acepta la interpretación de Von Rad, en la cual afirma haber una gran diferencia entre la historia de Israel, tal como ha sido reconstruida por la moderna ciencia hisıórica y la historia de la salvación, tal como ha sido escrita en los libros sagrados; pero, admitida esta diferencia, sostiene que la historia de la salvación depende de hechos que el historiador puede probar como reales. Wright, por su parte, también admitiría que los hechos centrales, en que se basaria la le, pueden ser constatados científicamente, pero admite que las acciones de Dios no son pura historia sino hisloria interpretada por la fe, una proyección de la fe en los hechos, proyección que es considerada como el signilicado verdadero de esos hechos. Von Rad, por su parte, sostiene que las narraciones bíblicas no pueden ser tenidas como fuente segura de información histórica ya que, a pesar de su base factual, su grado de historicidad es discutible; sin embargo, sostiene como categoria fundamental de su teologia lo que debe llamarse hisforia de la salvación.

En toda esta discusión, la hisıoria es vista más como ciencia histórica que como realidad histórica, se atiende más al carácter histórico de la constatación que al carácter histórico de lo consıatado. Se acepta, por ejemplo, que el conjunto de narraciones aparentemente históricas del Antiguo Testamento seria un cuerpo literario, que merecería más el nombre de story (relato) que el de history (hechos históricos científicos comprobados); se trataría de narraciones que quieren parecer históricas ('history-like'). Con ello más que información lo que se pretende transmitir es un mensaje, un sentido, utilizando para ello el genero ficción, de modo que su efectividad es independiente de si ocurrió o no 
Io que se dice haber sucedido. Se iralaria de relalos paradigmálicos o milos, que pretenderian expresar algo profundo y permanente de gran significación para el hombre: no en diflicil aceptar yue claboraciones posio icas puedan captar cl carácter real de un suceso más adecuadamente que una descripción puramente lactual. Asi, lo gue se narra en el Exodo como acción de Dios busca mostrar que en lo narrado hay un significicado profundo para la comuniclad, a la cual se le proporciona una revelación de Dios, no precisamente sobre un hecho particular, sino sobre valores y significados permanentes. No es, enton-

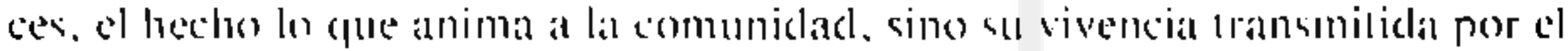

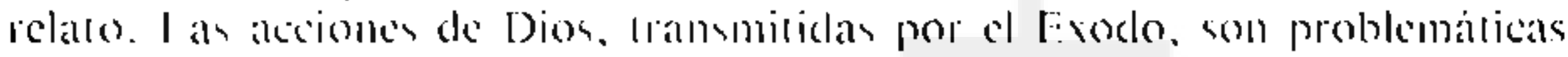

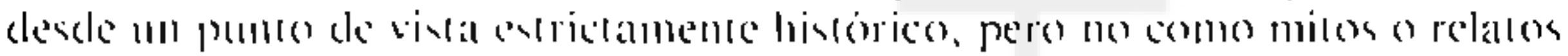
paracligmatcicos, que son significativos por la luz que arrojan sobre aspectos esencialer de la condicion humana.

Sin embargo, el texlo biblico, como lo reconoce Mircea Eliade, no presenta a Yaluve como una divinidad oriental, creadora de gestos arcuetipicos, sino como una personalidad que interviene sin cesar en la historia y que revela su voluntad a través cle los acontecimientos. En el caso cspecílico del Exodo se introduce puntualmente una novedad histórica no por una recurrencia necesaria, sino por una libre intervención de Dios, que es experimentada como tal por un pueblo determinaclo en liempos y lugares especificos. Por este camino se abre paso la revelación del poder transcenclente de Yabvé: lo innpredecible de la experiencia historica es celebradia como una revelación del poder transcendente de Yahvé. un poder que cambia la historia y que en el cambio histórico muestra lanto la contingencia humana como la esperanza humana. Yahvé cs más grande de lo que puede esperarse de cualquicr condicioinalidad histórica. Se apunta asi a la historia humana como campo privilegiado para mostrar la irrupción transcendente de Dios como novedad imprevisible que abre la contingencia humana a la esperanza divina. La experiencia humana no queda cerrada sobre si, sino abicrta a la esperamza puesta en la intervención divina.

Pero es inenester insistir más en por qué se recurre a la historia o, en su caso, al género histórico para mostrar la presencia reveladora de Dios. ¿Será porque en el campo histórico cs máls fácil la prucha apologética de la razonabilidad de la le o porque los hechos históricos maravillosos arrastran más a la confesión religiosa? Tal cxplicación racionalisla o psicosocial no cla razón ni clel texto sagrado ni de la experiencia del pueblo. Es cierto que se recurre a hechos palpables y llamativos, a signos y portentos, al mosirar que la llamada de Moisés al pucblo para salir de la opresion de Egipto, está lunclada y amparada en la voluntad y el poder de Yahue. Pero este recurso no es para conlirmar la razonabilidad de nuestra aceptación creyente de lo que alli ocurrio o el significado transcendente de lo que alli ocurrió, sino con el objeio de confirmar la propia acción histórica del pueblo que era invitado a salir de la opresión para llegar a la tierra de promisión y con el objelo de probar en esa acción hisıórica quién y cómo cra su Dios. La hisloria se convierte asi en probación de Dios porque es en si misına mostración de Dios, y sólo en la historia es captado Dios como es en relación al hombre y el hombre como es en relación con Dios (incluimos aqui por extensión la experiencia biográfica y personal del hombre, 
que como tal no es propiamente histórica, pero que tiene caracleristicas de hisloricidad, que permiten esa ex(cnsión). Si Dios no luera cantado en la historia como Señor de la hisloria, esto es, como Dios que interviene en ella, no seria captado como el Dios pleno, rico y libre, misterioso y cercano, escandaloso y esperanzador: seria capiado como el molor de los ciclos naturales, como paradigma de lo siempre igual, que puede tener un después, pero no un lururo abierto y en ese sentido como impulsador y lal vez. fin o meta de una evolución necesaria. Pero Moises acude a Yahvé y a las acciones de Yahvé no para reiterar lo mismo, sino para romper con el proceso, y es por esta rupeura del proceso por donde se hace presente on la historia alyo gue es mas clue la historia. En este senticlo es menos importante que esto se logre a través de una 'coyuntura' y no a través de un milagro formal, porque esa coyuntura tiene posibilidades de presentarse como novedad que rompe la normalidad de la experiencia.

No es nada obvia esla selección de la historia como lugar teofánico, como lugar privilegiado de la manifestación y allto-donación de Dios. A otros pueblos les ha parcciclo mejor acercarse a Dios a traves de la naturaleza con to cue ćsla liene de majestuoso, insondable, de inapelable para el hombre o, en el otro extremo, a través de la experiencia interior subjetiva o intersubjeliva. Puede decirse que la hisıria engloba y supera lanto el ámbito de lo natural como el ámbito de lo subjelivo y personal y en ese sentido, lejos de excluirlos, los enmarca y polencia. Pero sin la hisloria queda absolulamente reducido el ámbito de revelación y de donación de Dios; al contrario con la historia queda, por un lado, abierı lo que la humaniclad y con ella la realidad entera puede dar de si y, por olro lado, y, ell consecuencia, queda abierla la posibilidad elcctiva de mosirarse lo que es Dios para el hombre y el hombre para Dios. En la historia no puede darse Dios de úna vez por lodas como es el caso de la naturaleza, aun admilido el caso de una cvolución creadora (Bergson) o de una creación cvolvente (Zubiri); cn la historia se cucnta con la posibilidad de una revelación y autodonación permanente, no sólo por parle de quien la recibe sino, lo que es inas radical, por parte de quien la da. La naluraleza puede ser escrutada cada vez más lanto en la lejanía del pasado originario como en la profunclidad de sus elementos, pero esa maluralesa está ya dada e incluso su evolución está fundamenalmente lijada, mientras que la historia es el campo de la novedad, de la creatividad, nero un canıo doncle Dios sólo puede revelarse "mas," si se hace cfecrialmente "más" hisloria, esto es, una historia ma yor y mejor que lo que ha sido hasla este momento. Para Kant lodavia dos son las cosas que llenan el animo de admiración y respero. siempre nuevas y crecientes cuanto con más frecuencia sc ocupa de cllas la refexión, el cielo witrellado sobre mi y lat ley moral on mi:15 fue Hegel quien vio leoréticamente la historia como lugar de más altas admiraciones, pero fue antes la revelación vetero y neotestamentaria la que dio nor hecho que cn la historia se daba, más que la plenitud del ser y de la realidad, la verdad y el don de Dios, lo cual llevará en la concepción del Nuevo Testamento hasta la divinización de un hombre y en él de la humanidad entera.

La historia, por otra parte, lal como es vivida y comprendida en el Antiguo Testamento está abierla al futuro. Moisćs habla cle un pasado en un pre- 
sente hacia el futuro: es el Dios de los padres el que está viendo la opresión presente de los hijos en Egipto y el que los lanza hacia un futuro que vendrá por la promesa de Jahué en alianza con su pueblo. No basıa con un Dios de los padres, recibido en una experiencia que ya pasó, por más que siga viva en el pueblo; se'trata también de un presente, el presente de un pueblo oprimido y explotado, en el cual se reasume la experiencia pasada de los padres y se la renueva por la experiencia histórica, la cual en su negatividad obliga a volverse al Dios de vida, libertad y unidad social; se trata finalmente de un futuro de promesa y esperanza, el cual anula esa negatividad y recupera de modo nuevo la experiencia antigua, un fuluro en el cual colaboran Dios y el hombre y que dependerá, aunque de distinto modo, de la fidelidad de Dios y de la correspondencia humana. Una experiencia de opresión y de liberación hace que, desde la perspectiva de Dios, la opresión se vea como pecado y la liberación como gracia; hace que Dios se descubra como un Dios que no es sólo perdonador, sino que sobre todo es efectivamente liberador. Este carácter estrictamente futuro -el cual no sólo está más allá, sino que se hace actuante proyectivamente en el juego promesa/esperanza, acción de Dios/respuesla del hombre- es el que permite la revelación histórica de Dios y el que obliga a los hombres a abrirse y a no quedarse cerrados en ninguna experiencia ya dada ni en ningún limite definido: es el Deus semper novus como una de las formas de presentarse el Deus semper masor. La historia es asi el lugar pleno de la transcendencia, pero de una transcendencia que no aparece mecánicamente sino que sólo aparece cuando se hace historia y se irrumpe novedosamente en el proceso determinante en permanente desinstalación.

La historia es también lugar del pueblo. La experiencia de Moisés en la montaña santa no es la experiencia de un solitario, quien se en rrenta interiormente con la divinidad y luego transmite esa experiencia para que cada uno la reproduzca interior e individualmente. Al contrario, Moisés parte de uлa experiencia histórica que es la experiencia de su pueblo. Vive inicialmente de lo que ha recibido, de lo que se le ha dado de su pueblo en transmisión tradente (Zubiri). Ya adulto vive la experiencia colidiana de su pueblo e incluso participa violentamente en ella. Sólo después se retira a reconsiderar desde el Dios de los padres lo que puede hacer. Su intento primario no es hacer algo en lavor de Dios, sino hacer algo en favor del pueblo, aunque este hacer del pueblo sea considerado desde la perspectiva de Dios. Parte de un hacer del pueblo, retlexiona sobre este hacer delante de Dios y regresa al pueblo a trabajar conjuntamente por ese pueblo elegido y por el Dios que le ha elegido. Su punto de partida no es sólo el pueblo, sino la experiencia socio-politica del pueblo y su punıo de llegada es también la acción socio-politica de ese pueblo. Todo ello no como punto de apoyo para saltar a la experiencia de Dios sino, al contrario, es la experiencia de Dios la que se subordina a la acción salvadora del pueblo, para después elevar a ese pueblo hasta la actualización agradecida de su elección. hasta el reconocimiento de que sólo Yahvé es su Dios. Es en este hundimienıo de la acción divina y de la realidad divina en los problemas de la historia doncle la experiencia rompe sobre sí misma y queda abierta a algo que la supera por

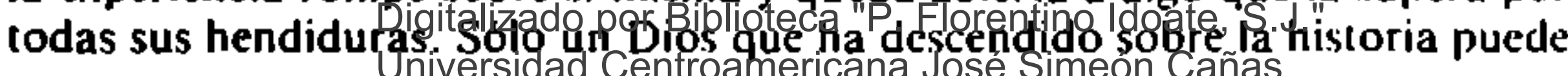


hacerla ascender hasta él. Pero esto se realiza en la historia de un pueblo. Como bien ha notado North, en el primer libro del Pentateuco se habla de figuras singulares, mientras que en el segundo libro el sujeto es Israel como entidad colectiva. ${ }^{16}$ Sólo la plenitud del pueblo, la cual no excluye la riqueza singular de personajes como Moisés, es capaz de manifesıar al Dios verdadero, quien no se encierra en la subjetividad solitaria de los grandes héroes, sino que se hace presente en los dolores, en las luchas y esperanzas de las mayorias populares. No en vano el articulo fundacional de la fe de Israel es la liberación de 10 do un pueblo oprimido, un pueblo que tuvo que salir de la casa de esclavitud, porque así to quiso Dios aunque lo realizó por intermedio de Moisés. ${ }^{17}$ Este articulo fundacional no es, pues, algo referido a Dios solo, a un Dios separado de la historia humana, ni siquiera a un Dios que da sentido a la vida individual y que proyecta su plenitud fuera de la historia; al contrario, es a partir de la historia y en la historia misma donde se hace presente como hecho religioso fundamental y fundacional, no sólo no distanciado del proceso socio-político, sino fundado en él y revivido en él. El punto de arranque es la opresión de un pueblo determinado con caracteristicas bien precisas que Dios y los hombres de Dios no pueden tolerar. Se trata, en efecto, de los antepasados de los isrelitas, quienes habian entrado libremente a Egipto y fueron asimilados a los Api. ru, prisioneros de guerra, y consıreñidos como ellos a los trabajos emprendidos por Ramses II en el delı; los egipcios no quisieron perder esıa mano de obra gratuita y consideraron la protesta de los israelitas como una rebelión de esclavos y su huida como una evasión de prisioneros. ${ }^{18}$

Es en esta experiencia y por esta experiencia histórica donde se revela el nombre de Yahvé. La teofanía nace de una teópraxía y remite a una nueva teopraxia: es el Dios que actúa en la historia y en una historia bien precisa quien puede descubrirse y nombrarse en forma más explícita y, si se quiere, en forma más transcendente. Aun sin argumentar etimológicamente sobre el sentido preciso del nombre revelado en la teolania de la zarza ardiente, no parece dudoso el sentido que debe darse al origen histórico del nombre divino, a su revelación histórica. Y esto es lo que va a quedar como regalo y posesión permanente del pueblo, no lanto el nombre separado de Yahvé, sino el nombre de Yahvé asociado a una acción histórica: "Yo soy Yahvé, su Dios, que los he hecho salir del pais de Egipto. "19 Y es en esta experiencia histórica donde puede formularse la alianza fundamental del "yo seré su Dios y ustedes serán mi pueblo." Para Israel su Dios queda definido por esa presencia divina, que hace salir al pueblo de la opresión del Egiplo; Israel llega 'más' a Dios y de distinta forma que en el caso de los padres, porque ha experimentado en su historia nueva algo nuevo de Dios. La acción de salir de Egipto, la salida del lugar de la opresión material - no consta con la misma evidencia que en Egipto se le impidiera al pueblo el culto de su Dios-, en vez. de ser una acción profana, es el lugar originario de una nueva experiencia revelante de Dios, tanto que respecto de ella es como aparece la revelación más explícita del hombre y del ser del Dios verdadero. La transcendencia no está aquí en salirse del pueblo y de sus luchas, sino en la potenciación de ese pueblo para sus luchas, en su paso de la tierra de Egipto a la tierra de Canaán. La revelación del nombre y la 
teofania entera es para que cl pueblo sacuda su yugo y se ponga en inarcha a la busqueda de una tierra nueva. I.a experiencia y el recuerdo de la salida y de la marcha es lo que mantendra viva la cxperiuncia de Dios en las generaciones venideras. Incluso cuando la reviviscencia sea ya fundamentalmente cultual, se pretenderá alimentar esa reviviscencia con el recuerdo de una historia y con el recurso a ella.

Desde esta perspectiva la preșunta de si es Yahvé o es Moisés quien saca al pueblo de F.giplo no admile la respuesı simplisıa de que es Moisés (interpretación racionalista o naluralisı) ni la respucsta asimismo simplista de que es Yalsé (imerpreación supramaluralisa). Ni Yahvé saca al pucblo sin Moisés ni Moisés sin Yaluve. [iste "sin' es absolutamente positivo y esential. Indudablementc el Exoclo plantea acciones clecisivas que serian propias y exclusivas de Yahvé (plagas, Mar Rojo, malná, elc.), mientras que Moisés no hará nada que no sea por mandato o inspiración de Yahvé. Pero si examinamos más de cerca esta presunta separación vemos que tiende a desaparecer. Asi, se dice indistintamente que el Faraón endurcicio su cora ${ }^{2} n^{20}$ y que Yalivé endureció el corazón del Faraón. 2I Lo mismo aparece en el caso de su obstinación.22 Las mismas plagas quedan reducidas en su significado [rente al milagro mismo de la pascua en cuya noche Israel fue liberado milagrosamente de Egipto, milagro en el cual la participación humana és mucho más evidente. ${ }^{23} \mathrm{Y}$ aún por lo que loca al carácles 'milagroso' de las plagas, éstas no aparecen como algo separado - una especie de signo en los cielos - sino como algo que tiene una finalidad histórica - la salida clel pueblo de Egipto-, que toca a realidades importantes para la vida social y económica de Egipto y que no se lleva a cabo al margen de la actividad de los agentes humanos. Yahvé aparece asi como el momento transcendente de una única praxis de salvación, aquel momento que rompc los liniles de la acción humana y/o rcconduce el sentido más prolundo de esa acción. Esto no supone reducir Dios a la historia, sino que supone, al contrario, clevar la historia a Dios, elevación sólo posible en cuanro antes ha descendido a ella el propio Yahvé a ıravés de Moisés, de Yahvé qaje interviene por que ha escuchado el clamor del pueblo oprinido.

Es, pues, históricamente cvidente (en el marco de la historicidad que sc quiera atribuir criticamente al relato del bxodo) que Moisés y sus acciones históricas juegan un papel relevante en la acción salvifica que sunone la salida del pueblo de Egiplo y en la interprelación transcendenle de esa acción dada al pucblo a laves de Moises. Hablar aqui de instrumemalidad, de elevación. elc., es recurrir a cxplicaciones y racionalizaciones, las cuales pueden ser oporlunas. sicmpre que no oscurezan el hecho lundamental. la accion histórica decisiva de Moises y la intrinsecidad de esa acción histórica respecio de la acción formalmente divina. la cual se presenta en unidad indisoluble con aquella. Los autores creyentes del Exodo aceptan como evidentc que es Dios el aulor principal cle estas hazañas. pero dan tambićn por evidenle que Moisés es el brazo de Yalué y que su acion hisiorica es sin más la acción salvilica. Lo que para los ojos no creyentes es la acción de un caudillo religioso, eso mismo y no oura cosa es para los ojos creyentes la acción de Dios: éstos no hacen más que descubrir la iranscendencia llena de graluidad quic se hace libremente presente en la acción 
histórica. Esıo no significa que cualquier acción histórica sea susceptible de la misma lectura, porque esa acción histórica debe tener un detcrminado conteniJo (no cualquier contenido es igual para la revelacion que Dios ha quericlo hacer de si mismo) y en ese contenido debe hacerse presente de modo especial Dios. Con qué criterios discernir unos acontecimientos históricos de otros es algo que aqui no toca dilucidar. por más que sea un punto csencial tanto en una reología de la revelación como en una teologia de los signos de los tiempos.

I.a pregunta, por ianio, de qué hay de profanos de qué haly de sagrado én la narración del Exodo carece de sentido. La descrincion profana de esta acción la podria haber dado un historiador racionalisia, pero en ese caso, desde la perspectiva del creyente, se trataria de una mutilación lograda por abstracción de uno de los elementos esenciales de la uniclad histórića. La descripción sagrada de la historia de Israel consistiria en el extremo opuesto en la enumeración de presunios elementos transcendentes o sobrenalurales los cuales sólo incidental y parabólicamente tendrian que ver con los hechos históricos, lo cual supondria también una inutilación lograda por abstracción separaliva. Nada de esto aparece en el Exodo y en el resio de los libros históricos y proféticos. Lo que si puede observarse, en cambio, es que en una única historia hay acciones en ravor de Dios y del pueblo y hay acciones en contra del pueblo y de Dios: hay praxis hisıórica de salvación y hay praxis hisıórica de perdición, hay praxis hisıórica de liberación y hay praxis histórica de opresión. Salvación y liberación que es, en primer lugar, una salvación y liberación malerial, sociopolitica, plenamente real y constatable y que sóto en un segundo momento aparece como lugar privilegiado de la revelación y de la presencia de Dios, donde cierlamente esie segundo momento no es un puro reflejo mecánico del anlerior sino algo que ha necesilado la superación de la acción histórica por una intervención especial pero intramundana de Dios. Dios se ha hecho libremente presente en la historia de un modo peculiar en relación con un pueblo y su cstado de postración: cuando alguien se pone ell contacto con ese pueblo y su postración se pone en conlacio con ese Dios que aclúa en la hisioria. En contacto de gracia y justificación si va en la línea cle la justicia y de la liberacion; ell contacto de pecado si va en la línea de la opresión y del limite. La teopraxia es el punto inicial del proceso salvador cono el imperio del pecado y del mat es el punlo inicial del proceso condenador. Moisés entra de lleno en la tcopraxia de Dios, mientras que el faraón culra de lleno en la negación del Dios de la vida y de la libertad. aal ves en nombre del dios que sostiente su modo de dominación. Como su posición es distinta en la historia cle la salvación, lambién es distinta la leofania que les corresponde: para Moisés y para su pueblo es la teofania de un Dios liberador, para cl faraón y su pueblo es la teofania de un Dios castigador. Pero la liberación y el castigo es a través de hechos históricos. Sólo si llega a esta leofania se completa la teopraxia y se muestra la plenitud de la historia, la plenilud de Dios en la historia. Y desde esta teofania siempre renovada pucde regularse lo que tiene que ser la praxis hislórica de la salvación.

La transcendencia histórica velerolestamentaria no esıá, entonces, en que 
por medio de relatos se hace presentc paradigmáticamente lo que Dios quiere del hombre en la historia. Está más bien en que se hace presente en la historia, auncue el relato que cxprese esta presencia no sea criticamente histórico. Lo paradigmático está, enıonces, en que donde se repila históricamente lo que en la escrilura se expresa como teopraxía, entonces puede verse en esa praxis hislórica determinada una teofanía. Es lo que ocurre en los casos de liberación histórica, cuando el pecado y la negación de Dios son manifiestos y cuando, por lanto, es preciso poner indo el poder del Dios cristiano en favor de la superación de ese pecado. Si el perdón del pecado sólo se da por la gracia, la anulación del pecado objelivado sólo se da por la presencia objelivada del poder de la gracia.

Esra praxis de salvación no tienc. sin embargo, por qué entenderse en términos puramente éticos, sobre todo si las obras de la ética se entienden como separadas de la le que pone en contacio con el Dios salvador. Mucho menos en ièrminos de una praxis meramente politica. La llamada politización de la fe, que inejor deberia llamarse historización de la $\mathrm{Ce}$, no consisle en decir que la acción salvifica se reduzca a la transformación de las estructuras sociopoliticas ni siquiera a la sublimación de las estructuras históricas, más abarcadoras que aquellas. Consiste en decir que la salvación no llega a su plenitud, si no se alcanza esa dimensión hislórica y, en su caso, esa dimensión polílica. No consisten tampoco la politización y la historización en consecuencias éticas que deben sacarse de la $\mathrm{re}$, pero que ya no tienen que ver con la fe misma, con la salvación, o, como diremos neolestamentariamente, con el reino de Dios. Precisamente, la unidad total de una sola historia de Dios en los hombres y de los hombres en Dios no permite la evasión a uno de los dos extremos abstractos: 'sólo Dios' o 'sólo el hombre";' pero tampoco permile quedarse en la dualidad acumulada de Dios ' $y$ ' Jel hombre, sino que afirma la unidad dual de Dios 'en' el hombre y del hombre ' $\mathrm{en}$ ' Dios. Este 'en' juega una distinta funcion y tiene una distinta densidad cuando la acción es de Dios 'en' el hombre y cuando la acción es del hombre 'en' Dios, pero siempre es el mismo 'en.' Y por eso, no es una praxis meramente politica, ni meramente histórica, ni meramente ética, sino que es una praxis historica transcendente, lo cual hace patente al Dios que se hace presente en la acción de la hisioria. Este momento puede darse de dos modos: uno virtual, pues aunque sigue con gran proximidad lo que seria una praxis cle salvación, no alcanza a conocer ni a nombrar explícitamente al Dios presente en esta praxis y quien es su último posibilitador; otro más formal y expreso, dentro de esa misma praxis se encuentra y reconoce a Dios, de modo que ese reconocimiento ilumina, critica y anima la propia acción. El ejemplo cle Moisés es en esto significalivo: su carácter de conduclor del pueblo no excluye su carácler de persona individual y su carácter de actor politico no cxcluye, antes al contrario, reclama el recurso a Dios hasta el punto de que la teopraxia se hace en él teofanía y ésta a su vez remite a una nueva teopraxia.

Esta afirmación, sin embargo, no permite decir que la liberación del Exoclo sólo tiene carácter salvífico en cuanto está ordenada al culto de la alianza que se celebró en el Sinai. Puede aseplarse, como afirma Urs von Balthasar (IIIC "la primera liberación apunta inmediatamente a una salvación más que 
politica en la aliam a del Sinai y en el culıo mandado nor ley alli mismo." 2.1 Efectivamente, se da la primera liberación y luego sucesivas liberaciones, cuya funclamentación es más explicitamente religiosa y cultual. Pero cualquicra sea el origen de estos relatos, 25 el orden real cle funclamentación es bien preciso: el culto -otro es el problema de lá alianza misma- no es el que da el significado a la liberación de Egiplo, sino que es ésta la que da su significado especifico al culto, el cual celebra y saca las consecuencias explicitas de la experiencia historica tenida, de la praxis historical que se tuvo. El culto del Simai es verdadero cullo porcue es de un pucblo el cual realmente ha encombrado em una praxis de

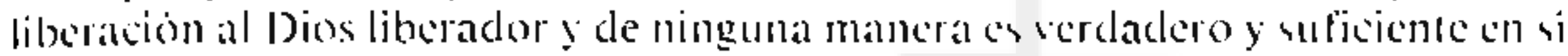
mismo. Pol eso, no es lácil estar de acucrdo con lo que sostiene la Comisión reológica imernacional en lo yue se reliere a este punto: "el objelivo de las necesiclades senticlas en los dilerentes casos particulares es un elenento de menor imporlancia; lo que prevalece es la experiencia en virtud de la cual solamente sc espera de Dios la salvación y el remedio. No se puede, pues, hablar de este género de salvación. en cuanto que alecta a los derechos y al bien del hombre, sin cilar al mismo tiempo roda la reflexión teológica scgún la cual es Dios y no el hombre, el que cambia las siluaciones."26 Es plausible pensar que el hombre velerolestamentario no veía las cosas así. Para él, como para el hombre actual oprimido de América Latina, cl objelo de las necesidades sentidas es funclamental, porque Dios no apareceria como liberador del pueblo -artículo de fe para el pueblo judio - si no se hubiera dado esa experiencia histórica de salvación; decir olra cosa es despojar cle su carácter histórico tanı a la historia misma como a la revelación. En segundo lugar no se puede decir que sólo de Dios se espera la salvación y el remedio, cuando Moisés y el pueblo jucgan un papel tan importante en la liberación; de ahi que alïmar que es Dios y no el hombre quien cambia las situaciones es una frase formalmente falsa, deformadora de la praxis crisliana y favorecedora de quienes si pretenden cambiar las situaciones desde una perspectiva de dominación y de pecado. Son, como veremos después, las acciones cerradas del hombre las que empecaIan y condenan la historia, como son las acciones abierlas del hombre las que la agracian y la salvan. Ciertamente. la apertura y el cierre son respecto de Dios y de su acción, pero este 'tener que ver' no es en modo alguno la exclusión del poder formalmente salvilico y translormador de la acción del hombre, no sólo respeclo de sí mismo, sino respecto de la historia.

La transcendencia histórica veterotestamentaria puede y clebe estudiarse en más lugares que en la acción liberaclora cle Moisés y puede y clebe atender a más aspectos de los aqui señalados. Pero los aqui expuestos con ocasión de la pascua judia original muestran puntos esenciales de lo yue puede ser una iranscendencia histórica. La historia es cle modo especial campo de la acción divina. Aunque los teólogos no descartan en sus juegos mentales la posibilidad de que Dios hubiera podido darse 'sobrenaluralmente' a la naluraleza puramente material, a la naturaleza no historizada ni personalizada, lo más plausible es pensar que su comunicación personal, personal por parte cle él y personal por parte de quien la recibe, sólo se puede realizar en lo biográfico y en lo histórico. Esto nos llevaria a considerar una comunicación y una presencia de Dios en la naturaleza como contradistinta de una comunicación y una presencia de Dios 
en la hisıoria: acjuella seria lugar más propicio para la que llaman prescncia natural de Dios y esta seria lugar más adecuado para la que llaman presencia sobrenatural de Dios. Volveremos más larde sobre esta mancra de hablar inexacla. L.o que en este momento imporla es subrayar cómo la hisloria de Isracl no sólo ha descubierto la clensidad real de lo histórico, sino que ha hecho de lo histórico el lugar más rico de la presencia y de la donación de Dios.

Podrá decirse que la transcendencia histórica veterotéstamentaria no es la mancra definitiva de la transcendencia hictórica, lal cono ésta se ha ido contïgurando en el curso de la revelación! y del clesarrollo hislorico. Fvidentemente

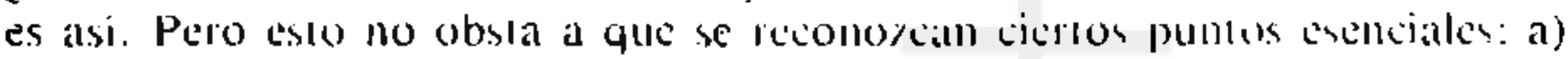
aquella transecendencia inistorica es la que ha dado paso al ot ras transcendencias históricas; b) aquella transcendencia historica toca elementos esenciales clel hombre y de la sociedad que no pueden ser dejatos fucra y que en deserminadas circunstancias históricas pueden alcanzar relorzacla actualidad; c) aquella iranscendencia histórica muestra la voluniad de Dios no sólo para el pasado. sino para el presente sin tener que caer por ello en lundamentalismos interprelativos; d) aquella transcendencia histórica va abriéndose desde si misma a formas ulteriores de transcendencia de modo que se conserva en éstas, aun transformada, proporcionándoles un dinamismo propio; e) el olvido o el menosprecio de la dimensión histórica velerolestamentaria mulila la revelación de Dios y vacia de una parte de su conteniclo a la transcendencia histórica neotestamentaria.

\section{La transcendencia histórica neotestamentaria}

Es consiatable que el Nuevo Tesiamenio olirece una clara especificidad al mostrar el problema de la transcendencia hisı́rica, esto es, al mosırar el qué y el cómo de la 'relación' Dios-hombre, salvación cristiana-realización humana. Hay una especificidad ncolestamentaria que no consiste primariamente en una especilicidad lógico-conceplual, sino en un paso cualitalivamente nuevo de un mismo proceso histórico de salvación. Este salto cualitativamente nuevo no es una ruptura; es màs bien una superación en la cual cobra nucra concreción y realización lo que en el estadio anterior era un lanteo algo indelcrminado, lanto por lo que tocaba al aspecto histórico como al aspecto transcendente. Esa indeterminación va a ser superada él terminos nuevon e incluso fijada con al. guna definilividad por la aparición con Jesús de la suprema forma de lranscendencia histórica, aunque esa de finitividad deja lodavia muchas cosas abierlas, que el Espiritu que nos ha legado Cristo resucilado nos irà ayudando a descubrir, discernir y realizar.

Para acercarnos a esta 'novedad superadora' y en paralclismo con lo que hicimos al estudiar la transcendencia histórica veterolestamentaria vamos a acercarnos a la figura de Jesús desde una perspecliva limitada, pero fundamental: Jesuis es el 'nuevo' Moisés. Si Moisés es quien constiluye histórica y reologalmente -en el relato del Exodo - al pucblo de Isracl, es Jesis quicn constituye histórica y teologalmente al nuevo pueblo de Israel. Este terna de Jesús como el nuevo Moisés es uno de los temas fundamentales del Nuevo Tes- 
tamento, el cual no se puede abarcar en unas pocas páginas, pero sobre el que existe una abundantisima bibliografia. ${ }^{27}$ Aquí sólo valınos a recoger alg̣umos indicios, que sean suficientes para plantear el problema y eshorar la solucion. Por otra parte, hay que reconocer también que la transcendencia histórica neotestamentaria no se agota en lo que puede dar de si la consicleración de Jesús como nuevo Moisés, lo cual supone un nuevo limite y una mayor limitacion a muestro trabajo. Pero el enfoque puede considerars sulicientemente correfu por cuanto en si mismo da luces imporiantes y por cuanlo esas luces no cfuclan opacadas por lo que pudiera decirse desde oiros pumbos de visla.

Para ello vamos recoger algunos de los aspectos lundamentales guc sobre este punto plantea el cuarto cvangelio. P’olriáa enfocarsc lambién el mismo problema desde la perspectiva del sermón de la montaña. clonde se cla la nueva ley al pueblo nuevo. Pero lal vez. pucelen decirsc cosas anteriores y más esenciales acudiendo al evangelio de Juan.

Como es sabido, la contraposición de Iesús con Moisés aparecc ya en el Prólogo del evangelio en un texto que ciertamente no responde al nivel primero del escrito 28 y que por eso no puede leersc como punto de arranque, sino como punto de llegada, que puede servir de horizonte. Dice asi el texto, tal como se lee en la Biblia española:

La prueba es que de su plenitud todos nosotros hemos recibido:

un amor que responde a su amor, porque la Ley se dio por medio de Moisés, el amor y la leaatad han exislido por medio de Jesús el Mesias.

A la divinidad nadie la ha visto nunca;

el único engendrado.

el que esiá de cara al padre, él ha sido la explicación

(Juan, I, 16-18).

Hay aqui una contraposición muy teologizada entre Moisés y Jesús. Se centra en dos puntos principales: Moisés dio la Ley mientras que el "amor fiel"29 se nos ha dado por Jesús, el Mesias; por olro lado, Moisés no pudo ver" a la divinidad, pero el Logos quien es más quc contemplador visual de la divinidad, si puede explicarnos cómo es Dios. La contraposición esiá hecha en términos estrictamente religiosos, pues tanto de Moisés como de Jesus no se afirman sus respectivas concretas realidades en su totalidad, sino sólo algunos de sus aspectos esenciales. Claro que indirectamente se reconoce un contexto histórico o, más bien, una destinación histórica, por cuanto la Ley va dirigida al pucblo y tiene un conjunto muy expreso de contenidos socio-politicos y por cuanto lo que nos garantiza el Logos del Padre es el amor por cxcelencia, un amor que ya no puede fallar y que es un don nuevo y renovador respeclo de la Ley. Esto es lo que fundaria la contraposición esencial entre el nuevo y el viejo Moists y, consencuentemente, entre el nuevo y el viejo Israel. La historia ha 
desaparecido casi por complelo para convertirse en pura realidad teologal y, a lo más, religiosa. Pero no es porque esté negada. La historia ha de vivirse en el nuevo eón con un espíritu distinto del antiguo; en aquél predomina la ley, en éste debe predominar el amor. Y podría verse en el amor una exigencia todavia mayor de compromiso con los demás y de compromiso histórico, porque el amor de Dios es un amor de entrega lolal hasla la muerle.

Si de esta contraposición en el prólogo se pasa a lo que sería el primer estrato redaccional del evangelio de Juan, en el que se hace presente una mayor incidencia del ambiente samarilano, ${ }^{30}$ aparece una visión mucho más matizada en la relación de Jesús con Moisés. Como texio básico estaria el relato de las palabras de Felipe en su encuentro con Natanael: "aquel del que ha escrito Moisés en la Ley, lo hemos encontrado: Jesús, el hijo de José, de Nazaret" $(1,45)$. La afirmación responde a un problema bien definido: tanto los judios como los samaritanos están esperando al Profeta, el Profeta que va a culminar la acción de Moisés según la antigua promesa: "Y Yahvé dijo: han hablado bien: Yo les suscilaré de en medio de sus hermanos, un profeta semejante a tí (Moisćs), yo pondré mis palabras en su boca y él les dirá todo lo que les ordenaré" (Dt. 18, 17-18). En el caso de los samaritanos se esperaba que ese profeta fuera realmente como Moisés y que, por tanto, lograse la liberación definitiva del pueblo de Dios, del pueblo samaritano en un nuevo éxodo. Esta cristologia primitiva del relato básico de Juan parte, por tanto, de la misma experiencia clásica de la unidad de salvación y de hisıoria: Dios es quien salva, pero salva a través de un enviado histórico y de acciones históricas; en la expectativa de los samarilanos, de acciones formalmente socio-politicas. Por eso tiene sentido el que Natanael acabe reconociendo que aquel Profeta del que se habla en la Ley sea verdaderamente el rey de Israel (Samaria). Precisamente porque Nalanael ha visto de algún modo en Jesús caracieres del Profeta confiesa que Jesús es el rey de Israel $(\mathrm{Jn} .1,49)$. En este contexlo queda aclarada la lunción de Juan el bautista y el bautismo de Jesús: la misión de Juan es análoga a la del profeta Samuel: los dos han sido encargados de designar y de manifestar al rey que Dios ha elegido para Israel. ${ }^{31} \mathrm{Y}$ es precisamente este carácter de rey el que en un segundo momento va a ser leido como Mesias: el mesianismo de Jesús tiene en el primer estrato de su presentación joanea una clara referencia a realidades históricas y políticas, por más que el fracaso de la realización histórica y politica lleve paulatinamente a concebir esta realización en términos de una transcendencia distinta, menos política y más religiosa. Pero siempre queda el principio básico, cargado de tradición histórica, de que el Bautista no es el Cristo ni el Profeta (Jn 1,49), mientras que Jesús es el Mesias y el Profeta anunciado por Moisés $(\mathrm{J} n .1,45)$.

La disposición de los tres primeros milagros, según la interpretación de Boismard mostraria cómo Jesús es el nuevo Moisés, quien va a cumplir definitivamente lo que Moisés prefiguraba. Tanto las bodas de Caná (Jn. 2,1-12), como la curación del hijo del funcionario real ( $\mathrm{Jn} 2,12$ ss) y la pesca milagrosa (Jn $21,1 \mathrm{ss}$ ) siguen el mismo patrón del Exodo $(4,1)$. Dios da el poder a Moisés de realizar sucesivamente tres milagros para mostrar que su misión entre los hombres es auténtica, de modo que éstos puedan creer en esa misión. Moises 
realizó tres milagros, tres signos (athorh, semeia), que son numerados como to son los signos de Jesús; Moisés realiza los tres milagros para que le reconociesen como enviado de Dios y lo mismo ocurre en cl caso de Jesús, quiell gracias a sus signos es reconocido como el enviado de Dios y, a este primer nivel de Juan, como el nuevo Moisés, quien era esperado según la promesa deuteronómica (D1 18, 18). Esta conexión del evangelio de Juan con los relatos del Exodo es tanto más de nolar cuanto que, en la tradición sinóptica, los milagros se conciben de ordinario como una consecuencia de la le en Cristo y no como un signo que debe conducir a los hombres a la re. ${ }^{32}$

Pero esa conexión de Jesús con Moisés, precisamente con el Moisés liberador y no con el Moisés legislador, pone en claro que aun en el caso de Jesús hay que andarse con cuidado a la hora de separar su acción hislórica cle su acción salvifica. Efectivamente, los tres signos de Moisés son para comprobar su misión divina y el carácler divino de la acción que queria emprender; ahora bien, esta misión y esa acción son de marcado carácter socio-politico. En este sentido, la referencia de Juan al Exodo es significativa. Hay también diferencias. Aunque los milagros de Jesús lienen un claro sentido terrenal, bodas de Caná, curación de un enfermo, pesca abundante, no son formalmente de carácler socio-político, sino más bien de carácter familiar. Pero esto es debido a que esos son los signos requeridos en esa situación concreta del anuncio de la fe, como serán otros los signos cuando las situaciones son distinlas, enirada mesiánica en Jerusalén ( $\mathrm{Jn} 12,12-19$ ), expulsión de los vendedores del templo ( $\mathrm{J} n$ 2,13 ss), curación del ciego ( $\ln 9,1$ ss). Pero siempre queda en pie la necesidad de signos y obras admirables que muestren o dẹnuestren, según los casos, la presencia y la voluniad de Dios. Que estos signoś sean consecuencia de la fe en Cristo o sean preámbulo de la fe en Cristo dependerá de los casos, pero en una y en oura interpretación nos encontramos con una conexión intrinseca del signo con lo significado; más aún podria entenderse el signo como la unidad del significante (el hecho histórico en su referencia al contenido salvifico) y del significado (el contenido salvifico hecho presente en el hecho histórico). El esquema de la unidad de lo transcendente y de lo histórico seguiria manteniendo su plena validez, aunque las circunstancias históricas y el estadio de desarrollo de la revelación lleven a concreciones dislintas, diferenciadas lanto por lo que se quiere manifestar y donar, como por la situación de aquellos a quienes va dirigida la manifestación y la donación.

Cullman da asi por comprobado "que el evangelio de Juan ha enlazado el acontecer central de la vida de Jesús con los restantes periodos históricosalvíficos." 33 Ciertamente la elevación de la serpiente y el maná se entienden de forma distinta en la tradición mosaica y en la tradición joanea. Pero, por otra parte, la sustitución del templo como lugar de adoración por la ligura misma de Jesús obliga a no espiritualizar ingenuamente el paso que da la tradición neotestamentaria sobre la veterotestamentaria.

No podemos proseguir nuestro recordatorio de la presencia del nuevo Moisés en el estrato más primitivo del evangelio de Juan. El que en otros estratos se haya deshistorizado el carácter mosaico de Jesús, la realización arquetipica de lo que en Moisés era sólo prololipo. no debe descuidarse al 
hablar de la lannscenclencia historica nevestamemaria. Pero el que se da una Iranscenclemalization de lo historico no quila que deba subrayarse que el primer nivel es hisiorico y hace relerencia para el pasado, para el presente y para

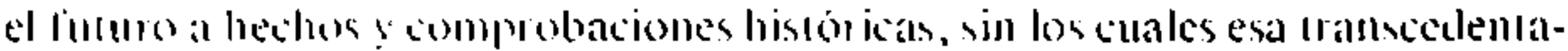
lización careccria de lundamenı y hasıa cierı punı de comlenido. La decidida hisiori/acion a guc somelc el crangelio de Iuan Ioda la polcmica de Jesús con las aumoridacles religioso-politicas judias - los 'judios" - y sobre todo a su juicio. mucrac : crucilivion prucba evidentemente quc esa Iranscendentalización no es huicla de las realidades hishoricas, sino ono modo de enlirentarse con ellas. mo menos efectivo y polimico que el de un enlentamiento en términos

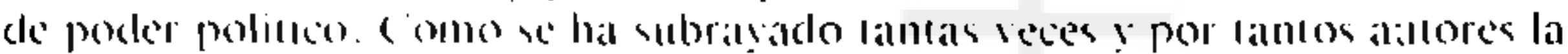
releremcia en lon relalos de la pasion a acusaciones mezcladamente religiosas ! politicas, si bien demuestra la tendencia interpresativa de sus acusadores en ver el faclor religioso conio indisolublemente unick al facror politico, lo colal les llevo a un desviación en la valoración de lo que Jesús hacia, al mismo tiempo demuestra que la presencia, las palabras y los hechos de Jesús no representaban una ruptura lal de la Iradición religioso-politica como para clejar de verle colno un rival peligroso. Querer interpretar esta ruplura, como si Jesús quisicra separar radicalmente lo salvífico de lo histórico y que los judios vieran en esto una negación de su Iradición lundamental y una amenaza a un poder mantenido por razones religiosas, sería una interpretación que desbordaria lo que los texios silstados lratan de comunicar o, al menos, el modo en que lo comunican.

Por eso de lo dichn tal vez no resulle exagerado sacar algunas consecuencias para nuestro problema, las cuales podriamos formular en las siguientes tesis: a) cl evangelio de Juan, que llega a las formulaciones más altas sobre la transcendencia de Jesús y sobre su divinidad, arranca de ver a Jesús como el nuevo Moisés, quien ha de desempeñar una función liberadora con su pueblo; b) Jesius se presentaria inicialınente a su pueblo - en este caso al pueblo de Samaria - como alguien que va a responder a su necesidad de liberación, a la necesidad de ser liberados no sólo religiosamente, sino, lambién hisıóricamenIe; c) esla liberación y presencia histórica de la salvación va a dirigirse por otros rumbos en una praxis distinla a la de Moisés, pero no va a abandonar ni el proposito fumclamental ni su forma originaria en lo que tiene de referencia constitutiva a lo histórico; una de las distinciones lundamentales es que ya no se va a conligurar la presencia liberackora de Dios como una leocracia, sino como una fuerza sin poder políico. Io cual va a transformar la realidad hisı́rica descle el pueblo precisanicute colltra los poderes que se presentan como leocrálicos y. consecuememenc. conu idolatricos, en tanto que son dominadores en nombre de Dios: e) esta llueva pracilica liberadora de Jesús lo pone en contradicción con los poderes de este mundo en lo que lienen de clominadores y lo conducen a la muerle, de modo que no pucde entrar con su pucblo a la tierra promerida, lo cual va a llevar a una reconsideración de la salvación histórica en tèrminos de escatologia (anto individual como colectiva; f) esta praxis hisıórica cle Jesús revela en él una nueva y definitiva presencia de Dios, la cual va a dar a la transcendencia especifica y plenamente cristiana nuevas perspectivas y nuevas dimensiones. 
Es claro, entonces, que este nuevo Moisés ha de dar lugar tambièn a un nuevo pueblo, a un nuevo Israel. Si el recuerdo y la presencia de Moisés asi como del pueblo al que Moisés acompañaba nos hablan de una continuidad histórica, el carácler de novedad con que sc presentan el "nucvo" Moisés, el 'nuevo' pueblo, la 'nueva' pascua, el 'nuevo' mandamiento, la 'nueva' ley. etc., nos hablan de una diferencia cualilativa, que tal vez. no deba entender'se en términos de ruptura, por lo que sin hablar de discontinuidad hay que hablar de algo distinto. El 'nuevo' pueblo de Israel, en efeclo, va constituyéndose en su incesante novedad ya en el Antiguo Testamento como algo que es, a la ve\%. el resto al cual va dirigida la promesa hecha, pero lambien como germen de la promesa que ha de cumplirse. Y se constituye o se va constiluyendo por la experiencia historica de un Cracaso politico, que pone en otra perspecliva la pro. mesa de Dios: los [racasos históricos, tanto en la rcalización del poder politico y del triunfo del poder de lsrael, como en la consecución de nuevas relaciones entre los hombres y de los hombres con Dios, van llevando a una lectura nueva de la promesa divina. Esta experiencia del fracaso es Iodavia más clara en los días del Nuevo Testamenıo, no sólo por el escandaloso final de Jesús como Mesias, sino por la destrucción misma del pucblo de lsrael y por el consiguiente paso a la constitución de una nueva forma de relacionarse religiosamente los hombres entre si y con Dios. El cambio se realizará entonces en dos direc. ciones: por un lado, el particularismo étnico de lsrael se abrirá a un universalismo, el cual también estaba más que apuntado en los Profelas, pero que supone una gran novedad por cuanto ya no sólo será Israel el salvado y el salvador, sino que el mundo entero será el salvado mientras se va dibujando una nueva figura de salvador, que es en una primera instancia histórica Jesús, pero que después necesitará prolongarse en la multiplicación de lugares y liempos; por otro lado, el esquema histórico de salvación del Antiguo Testamento, que ciertamente juntaba la fidelidad a Yahvé y a los preferidos de Yahvé con la plenitud de la vida, pero que, por otra parte, funcionaba teocrálicamente y desde el poder politico, se abrirá a un nuevo esquema hisı́orico en donde se perfeccionará y concretará la 'relación' de la santidad con el bien del mundo, pero en donde deberá desaparecer la imposición de la salvación desde arriba por los medios que tienen los señores de este mundo.

Es aqui donde aparece la Iglesia como lugar nuevo de salvación: lá Iglesia como el nuevo pueblo de Dios, al cual el nuevo Moisés ha dado vida y al cual le compete llevar adelante la historia de la salvación, animado del Espiritu que Cristo, muerto y resucitado, ha prometido. Pero, para nuest ro propósito, asegurar que la Iglesia es el lugar histórico nuevo de la salvación, no es suficientc. Aun aceptando que la Iglesia visible e histórica sigue mantenicndo por voluntad de Jesucristo y por asistencia del Espíritu ese carácter excepcional de lugar de la salvación, queda por preguntarse qué de esa Iglesia hisıórica está en capacidad de serlo y qué en esa Iglesia histórica lo está contradicienclo. Es el problema de encontrar en la Iglesia verdadera lo verdadero de la lglesia. Y esta pregunta por lo verdadero de la lglesia, que es posible no pueda separarse históricamente de lo falso de ella, como el trigo no se podria separar de la cizaña hasta el final de los tiempos, porque en esa separación se arruinaria la cosecha entera, no puede responderse sin cuestionarse dentro de ella y en ella, esto es, 
sin salirse de ella, por la transcendencia histórica cristiana, en el sentido de buscar aquellas realidades tangibles que son por sí mismas y según la voluntad de Cristo el lugar donde 'más' se revela el Dios cristiano, quien no gusla ni de la sabiduría que buscan los griegos ni tampoco de los signos que buscan los judios. Una nueva sabiduria y unos signos nuevos van a ser necesarios para que se realice definitivamente la promesa de que Dios está con nosotros, de que nosotros seamos su pueblo y de que el Dios verdadero sea realmente nuestro Dios.

\section{Búsqueda de la Iranscendencia hislórica cristiana}

Teniendo presentes las perspectivas de la transcendencia histórica veterotestamentaria y de la transcendencia histórica neotestamentaria podemos volver a preguntarnos por lo que deberá ser la transcendencia histórica cristiana. El problema tiene dos vertientes: por un lado, se trala de ver en qué 'relacion' se encuentran la llainada historia profana y la historia de la salvación; por otro lado, se trata de ver cuál es el aporte específicamente cristiano a ese momento de transcendencia histórica, en el cual lo transcendente se hace de alguna forma histórico y en el cual lo histórico se hace de alguna forma transcendente.

Para presentar el problema con cierta generalidad teórica, antes de entrar en un análisis más concentrado en la perspectiva de la teología de la liberación, vamos a esbozar brevemente dos puntos de vista europeos, uno católico y otro evangélico, en los que se expresa significativamente este problema.

Rahner en un breve ensayo titulado precisamente "Weltgeschichte und Heilsgeschichre",34 ha formulado ciertas tesis que, aunque pertenecen a un período de su pensamiento menos interesado en la proyección política de lo religioso, expresan en su conjunto puntos de vista que son fundamentales en su pensamiento: 1) la historia de la salvación acaece y se compenetra con la historia del mundo, porque la salvación acaece ahora, es aceptada libremente por el hombre y permanece escondida en la historia profana en la dualidad de su posibilidad de salvación y condenación; 2) la historia de la salvación es distinta de la historia profana, ya que la historia profana no permite dar una interpretación univoca respecto de la salvación y de la condenación, aunque ha de hablarse de una constante interferencia y coexistencia entre la historia profana y la historia de la salvación y de la revelación, no obstante que Dios por su palabra, que es un elemento contitutivo de la historia de la salvacion, ha segregado una parte de la historia para constituir esa parte como la historia de la salvación expresa, oficial y propia; 3 ) la historia de la salvación explica la historia profana en cuanto desmitologiza y desnuminiza, en cuanto la ve como antagonica y oscurecida, en cuanto la interpreta como existencialmente despotenciada y en cuanto la explica cristocéntricamente. En última instancia, la historia profana es la condición de posibilidad de la historia de Cristo que es también la historia de Dios semejantemente a como la historia natural en su materialidad y vitalidad es la condición de posibilidad del surgimiento del espíritu Cinito.

Pannenberg por su parte ha formulado también sus tesis a propósito de la 
revelación en su relación con la historia: 1) la auto-revelación de Dios no se ha realizado de una forma discrela, algo asi como en la forma de una leofania, sino indirectamente, a través de las obras de Dios en la historia; 2) la revelación no tiene lugar al comienzo, sino al final de la historia revelanie; 3 ) la revelación histórica está abierta, a codo el que tenga ojos para ver y tiene carácter universal; 4) "la revelación universal de lá divinidad de Dios no se realizó ı odavia en la historia de 1srael, sino sólo en cl destino de Jesús de Na/arel, en cuanto ell dicho destino aconteció anticipadamente el lin de lodo acontecer;" 5) el atontecimiento de Cristo no revela la divinidad del Dios de Israel como un suceso aislado y solo es comprensible a partir de la historia de Dion con lsrael; 6) en la rormación de concepciones no judias de la revelación en las iglesias crislianas de origen pagano se expresa la universalidad de la autorrevelacion escatológica en el destino de Jesis: 7) la palabra cle Dios se relaciona con la revelación como predicación, como precepto y como relato. ${ }^{35}$

Vayamos ahora a ver en contraste cómo trata la tcología de la liberación el doble problema que anunciábamos lineas arriba sobre la iranscendencia hislórica cristiana. Procedereınos por pasos a partir de lo que es la experiencia del creyente latinoamericano - claro esıá que no sólo la de ćl-, mayorilariamente perlenciente a los sectores populares inás pobres y oprimidos y, lambién, del creyente latinoamericano que se ha visto impulsado desde su fe a comprometerse politicamente en la conquista de la libertad a través de un proceso de liberación.

3.1. Aceptando que puede darse alguna diferencia entre lo que puede ser una historia de la salvación y la historia real que le loca vivir empiricamente puede decirse que en el fondo el creyente ve estas dos historias unificadas o, más bien, unidas en lo que pudiera llamarse la gran hisıoria de Dios. Esıa gran percepción supondria que se le presenta la hisıoria como un todo y que deniro de esa historia se presenta como una parte de ella lo que pudiera llamarse historia de la salvación, lo cual ciertamente no se reduce a la vida sacramental ni a la vida cultual o estrictamente religiosa, y además se da olra gran parte que, siendo en apariencia más prolana, constiluye también la gran historia de Dios con los hombres. A la pregunta de si la historia profana toma su sentido de la historia de la salvación y se subordina a ella, se responde así, planteando el problema en términos más hondos: la hisıoria de la salvación y la llamada historia profana quedan englobadas en una única historia a la cual sirvell, la historia de Dios, lo que Dios ha hecho con la naturaleza entera, lo que Dios hace en la historia de los hombres, lo que Dios quiere que resulte de su constante auto-donación que puede imaginarse como yendo de la eternidad a la eternidad. En este sentido, la historia de la salvación que culmina con la persona de Cristo se subordina a esa historia mayor de Dios. Podria decirse que en esta concepción se está viviendo aquello de Pablo cuando ve el designio secreto de Dios de "llevar la historia a su plenitud" haciendo la unidad del universo por medio del Mesias, de lo terrestre y de los celeste (Ef 1,9-10), "porque todo es de ustedes; Pablo, Apolo, Pedro, el mundo la vida, la muerte, lo presente y lo por venir, lodo es de usledes; pero ustedes son de Cristo, y Cristo de Dios" (1 Co 21-23). "Y cuando el universo le quede somelido, entonces también el 
Hijo se somelerá al que se lo somelió, y Dios lo scrá Iodo para lodos" (I Co $15,28)$.

Esta afirmación de la historia de Dios, como la verdadera historia conglobante de todo lo que ocurre en la historia y que no identifica la historia de la salvación con la autonomía de lo prolano, viene dada con la religiosiclad nopular y también con las Iradiciones religiosas precristianas, las cuales dan por obvio que Dios ha hecho y sigue haciendo a los hombres como a las demás cosas que existen. La predicación cristiana vino a insertarse en una Iradición religiosa anterior. en varios lugares todavia muy operante, baciendo connatural la

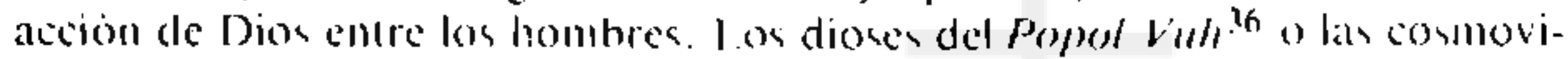
siones todavia operantes de pueblos como el k'ekchi' 37 sirven de sustrato a esta accplación de un mismo Dios quien comienza haciendo la lierra y el cielo para seguir estando después tras Ios acontecimientos naturales y, en alguna medida, también tras los acontecinientos históricos.

En esta historia de Dios, la fe cristiana da un puesto absolutamente principal al acontecimiento salvifico de Crisıo, pero esıo no supone una sumisión cesaropapista y/o religiosista de la llanada historia prolana a lo especifico de Cristo, como cabeza de la Iglesia y. por lanto, a la Iglesia como continuadora de la obra de Crisıo, aunque si supone una subordinación a lo que pudiera llamarse el Cristo histórico-cósmico. Ilamado a hacer que la historia entera sea efectivamenle una hisloria de Dios, que $\mathrm{cn}$ la lierra es la consirucción del reino de Dios. Ese Crisıo hisı́órico-cósmico liene su clave en el .lesús histórico de Nazaret tal como nos lo presenta e interpreta todo el Nuevo Testamento desde sus origenes y vida históricos hasta su condición de resucitado, señor del universo y de la historia. Con lo cual tenemos que el reino de los cielos es, en un primer momento, una semilla que se introduce en los campos del mundo y en la historia, para hacer de ésıa la hisıoria de Dios, un Dios que en delinitiva sea lodo en todos. En ese primer momento no se somete el campo a la semilla, sino la semilla al campo o, según la otra parábola evangélica, la levadura clel reino se introduce inodesta y eficazmente en la masa del mundo para hacerla fermentar y crecer.

Todo esto se expresa en la absoluta naturalidad con la que el creyente popular latinoamericano vive su relación con la naluraleza y vive el conjunto de sus relaciones humanas. Dedicarse sólo a lo religioso del reino sin atender a la esecial referecia que éste tiene con el inundo y con la historia seria, en definiti. va, Iraicionar la historia de Dios, dejar el campo de la hisioria a los enemigos de Dios. No hay, entonces, un reduccionismo de lo gue es la historia de Dios a lo que es la historia de la salvación cristiana en su sentido restringido, ni menos un reduccionismo de lo que es la historia de Dios a lo que es la historia de los acontecimientos políticos, sociales, económicos, culturales, etc. Más bien hay un intento de construir descle la fe y la operatividad cristiana en medio del mundo, que tiene su propia autonomia, como aquellas tienen la suya, la hisioria de Dios, en la cual confluyen, de distinta forma y con distinla densidad real, la acción de Cristo y la acción de los hombres, los clictados de la fe y los dictaclos de la razón. 
Quizá pueda parecer este modo de expresar el problema de la lamscendencia histórica cristiana un tanto abstracto. No es asi. La formulación de los conceptos, tal vez no acertada, no debe olviclar que se lrala de una expericulia originaria del creyente que ve lodo como una unidad en la que se ve inmerso y que debe respetar. Esta unidad se funda en la profuncla convicción cle que hay un solo Dios y Padre, de que hay una sola creación, de que hay un solo salvador, de que hay un solo reino de Dios y de que hay una sola excallologia. Lin solo mundo y una sola humanidad. No deben ir, ell consccuencia, y no pueden ir por un lado las cosas de Dios y por oro las cosas del hombre, sill yue esto sea confundir a Dios con el hombre. H:I mismo Jesús que como Crisr licapilulara en si todas las cosas se presenla históricamente para cumplir esa misión como el que ha venido a servir a los hombres y a dar su vicla por ellos: la lglesia, a su vez, deberá asimismo cumplir con su misión poniéndose al servicio de los hombres y dando su vida y su inslitucionalidad por ellos, sabiendo que asi se va realizando la gran historia de Dios. El ejemplo cle la vicla de Jesús sigue siendo criterio rundamental de cómo quiere Dios ponerse al servició de los honbres.

La estructuración de la historia de la salvación y cle la historia del inundo en lo que venimos llamando la hisıoria de Dios no implica la aceplación de una dualidad separada entre aquellas, subsumida en la unidad superior de ésıa, porque ésta no es sino la unidad estructural de las otras dos: la historia ilel mundo debe delerminar de múltiples formas la historia de la salvación y lá lisitoria de la salvación debe determinar de múltiples formas la hisıoria del mundo, aceptado que en ambas se juega la historia de Dios. Asi la historia del mundo, debidamente analizada y discernida - aqui estriba la importancia que Boff da a la mediación socio-analitica ${ }^{33}$ - es la presentación a la historia de la salvación de la tarea que en cada momento le corresponde, que en partc, aunque desde su propia especificidad, deberá conformarse según esta fundamental exigencia misional. Pero, al mismo liempo, la hisıoria de la revelación - aqui estriba la importancia que Boll da a la mediación hermenéutica ${ }^{\mathbf{7 4}}$ - debidamente interpretada tracará de orientar a la historia del mundo según lo que es la exigencia de la historia de Dios, la cual a su vez liene distinlas formas de manifestarse en los dacos de la revclación, en los signos cle los ticrnpos y aun en lo; más básicos condicionamientos de la naturaleza malerial. Asi se irá completando la auto-donación de Dios a la humanidad, la cual se cla no sólo en cl ambito reducido de una historia de la salvación entendida restriclivamente, sino en el ámbilo lotal de la historia. En èsı, sin embargo, viene prioridád axiológi ca la historia de la salvación en cuanto en ella se hace presente cle forına cininente la auto-donación de Dios sobre lodo en la ligura de Jesús y en la acumulación de la palabra revelada, sin olvidar, no obstante, como más tarde insisti. remos, que en lugares aparentemente muy prolanos como el de los pobres y empobrecidos de este mundo, se da una especial presencia c inlervención salvífica del propio Jesús, como mediador fundanental de la hisioria de Dios.

3.2. en estrecha relación con el punto anterior está el problema de qué hay de natural y qué de sobrenatural en esıa única historia de Dios.

Ya la misma formulación del problema origina cierlo desasosicgo. i,Sera 
mayor la diversidad surgida de los distintos modos de donarse Dios que la umdad surgida de que sea un único Dios el que se da de distintas maneras? Esta pregunta es tanto más válida si la referimos no al caso de la santificación y divinización de las personas, sino al caso de la presencia y la intervención de Dios en la historia. ¿Es distinta la obra de Moisés y la presencia de Dios en ella cuando saca al pueblo oprimido de Egipto que cuando le entrega la ley o celebra ritos religiosos? ¿Es distinta la obra de Jesús y la presencia de Dios en ella cuando da de comer a la multitud que tiene hambre, cuando arroja a los mercaderes del templo o cuando anuncia el reino de Dios e institucionaliza la cena eucaristica? ¿Llamaremos con razón a las más 'prolanas' intervención natural de Dios y a las más 'religiosas' intervención sobrenalural?

El creyente popular latinoamericano no ve y menos afirma reflejamente algo que en ese sentido pudiera llamarse intervención natural de Dios y algo que pudiera ser intervención sobrenatural; a lo más haiá esa distinción en lérminos de milagro, pero no en términos de una comunicación sobrenalural contradistinta de una comunicación natural por parte de Dios. Puede que aprecie cosas más o menos alejadas de Dios o en las cuales Dios se hace menos presente, pero no una división tajante entre lo que sea obra de la gracia y lo que sea obra de la naturaleza, esto es, entre lo natural y to sobrenatural. Aceptará, por ejemplo, que en los sacramentos Dios se hace presente de una forma, por decirlo así, más religiosa, pero no por eso desconocerá que el mismo Dios de los sacramentos se le hace presente en el destino de su vida y en el discurrir de los acontecimientos históricos. Más bien todo quedará incluido en la categoria de la voluntad de Dios: unas veces se pensará fatalisticamente que lal o cual cosa sucedió porque esa era la voluntad de Dios; otras veces se verá con toda claridad que tal o cual acción es contra la voluntad de Dios y esto no sólo o principalmente en el campo de las acciones personales, sino en el curso de los acontecimientos históricos.

Todo ello hace que la cuestión se plantce en términos distintos. La diferencia fundamental no es entre naturaleza y sobrenaluraleza, una vez entrados en la única historia de Dios que en la misma creación del hombre lo ha elevado a participar personalmente de sú propia vida divina, sino entre gracia y pecado. Hay acciones que matan la vida (divina) y hay acciones que dan la vida (divina); aquéllas son el reino del pecado; éstas son el reino de la gracia. Hay estructuras sociales e históricas que son la objetivación del poder del pecado y, además, vehiculan ese poder en contra de los hombres, de la vida de los hombres y hay estructuras sociales e históricas que son objelivación de la gracia y vehiculan, además, ese poder en favor de la vida de los hombres; aquéllas constituyen el pecado estructural y éstas constituyen la gracia estruclural. Urs von Balthasar ve bien que "el Nuevo Testamento pone [rente a Trente en primer término dos formas de existencia: la sometida al pecado ('hamartia') y la liberada de ese pecado gracias a Crisio," 40 pero no es justo cuando enjuicia a Medellín por hablar de estructuras injustas y opresoras, las cuales constituyen una situación de pecado diciendo que "las situaciones podrán ser injuslas, pero en si mismas no son pecadoras." 41 Las situaciones podrán no ser pecadoras, pero pueden ser objetivación del pecado y pecado ellas mismas en cuanto 
son la negación positiva de algún aspecto esencial del Dios de la vida. Pensar que sólo hay pecado cuando hay responsabilidad personal y ell cuanto hay responsabilidad personal es empobrecer injustificada y peligrosamente do do. minio del pecado. La leologia de la liberación anima a cambiar determinadas estructuras en busca de orras nuevas, porque en aquéllas ve pecado y cn éslas ve gracia, porque en aquéllas ve la negación de la voluntad de Dios y de la donación de Dios mientras que en ítas ve la voluniad de Dios y su donación alirmadas y realizadas. ${ }^{42}$

No quiere esto decir que sea ociosa la pregunia clásica por lo natural y lo sobrenatural. Pero no es la pregunta primera. La pregunta primera es ver lo que hay de gracia y lo que hay de pecado en el hombre y enl la historia, pern una gracia y un pecado no vistos primariamente descle un punto de vista moral y, menos, desde un punto de vista de cumplimiento de ieyes y obligaciones, sino vistos primariamente desde lo que hace presente la vida de Dios cnlre los hombres. Es ésta la que hace posible el cumplimiento de leyes obligaciones y no éslas las que traen consigo la presencia de Dios. No es la ley la que salva. sino la fe y la gracia, bien que una l'c y una gracia opcrantes y en su caso objeti. vadas históricamente.

Diclaminar que hay de pecado objetivo en la siluación que vive el pueblo lalinoamericano no requiere discernimientos especiales. Salıa a la visıa. Ha sido reconocido por Medellin y Puebla, denunciado mil veces por los obispos. apreciado clarividentemente por lo que podriamos llamar el sensus fidei de los pobres. Porque para los oprimidos creyentes de América I.atina la injusticia y todo lo que trae la muerte y la negación de la dignidad de hijos de Dios, no es meramente un efecto histórico, ni siquiera una falta legal; es formalmente pecado, es formalmente algo que tiene que ver con Dios. La muerte del pobre es la muerte de Dios, es la crucifixión continuada del Hijo cle Dios. Fl pecado es la negación de Dios y la negación del pecado va por caminos a veces ienoros hacia la afirmación de Dios, hacia el hacer presenle a Dios como dador dle vi. da. La percepcion de un mundo empecat ado por las ambiciones, los odios. las dominaciones es algo alimentado por la fe y por el senticlo cristiano de quienes viven sencillamente su fe. Es una de las formas de presentarse el pecaldo clel mundo, que Cristo vino a redimir y que cl cristiano debe urabajar por quitarlo, por hacerlo desaparecer del mundo. Pecado que en su generalidad no adinite muchas disquisiciones, pero que pucde presentarse comcriamente en lommas más suliles que necesitarán análisis tcológicos más cuicladosos.

3.3. Para profundizar algo más en esta única historia de Dios que se presenta fundamentalınente como una historia de pecado-ęracia pueden hacerse algunas reflexiones que parecerán un tanıo teóricas, pero que son iluminadoras para entender mejor to que venimos diciendo y taınbién pueden servir de orientación práctica.

Todo depende de cómo se entienda la creación. Si por creación se entiende un acto eficiente de Dios en el cual la crealura es un efecio scparado, que a lo más tiene una remota semejanza, la unidad de lo creado con el creador y la nosibilidad de entender una sola historia de Dios quedan scriamente dificultadas. 
Puede, en cambio, concebirsc la creación, como tantas veces apuntaba 7.ubiri en sus cursos, de otra manera. La creación seria la plasmación ad extra de la propia vida trinilaria, una plasmación libremente querida. pero de la propia vida Irinitaria. No se trat aria entonces de una causalidad ejemplar idealista, sino de una acción comunicaliva y auto-clonativa de la propia vida divina. Esta plasmación y auto-comunicación liene grados y limiles, por lo cual caclá cosá, según sus limiles, es una forma limitadia de ser bion: cha lorma limiracla mo es sino la maturaléa de cada cosa. 1.a comunicación de Dios, la plasmación ad extru de la vida divina, ha tenido un largo proceso y va orientada a la plasmación de esa vicla disina en la naturale/a humana de Jesus y billimamente al 'regreso' de roda la creación a su fuente originaria. En ese largo proceso se encuemlira la forma puramente malerial de la creacion, la forma de la vida en sus distintas lases y finalmente la forma de la humanidad y de su historia. El hombre como esencia formalmente abierla y la historia en su esencial apertura son las realidades clonde esa plasmación de la viclat lrinitaria pueden darse más y más, aumque siempre de lorma limitada, ahierta pero limitada, limitada pero abierla.

En esto consistiria el carácicr leologal de locla las cosas y especialmente el carácter teologal del hombre y de la hisioria. No seria sólo que Dios estuviera en rodas las cosas, según el carácier de cllas, pot esencia. presencia y potencia; sería que las cosas Iodas, cacla una a su modo, habrian sido plasmadas según la vida trinitaria y esıarian referidas esencialmemle a clla. la dimensión teologal del mundo creado, que no debe confundirse con la dimensión teológica, est ribaria en esa presencia de la vida trinitaria, que es intrinseca a lodas las cosas, pero que en el hombre puede aprehenderse como real y como principio de personalidad. De esta dimensión teologal hay estricta experiencia y a través de ella hay una estricta experiencia personal, social e hisiórica de Dios. ${ }^{43}$ Habrá grados y modos en esal cxperiencia, pero, cuando sea verdadera experiencia de la real climensión teologal del hombre, de la sociedad, de la historia y, en olra medicla, de las cosas puramente materiales, será experiencia, probación física de la propia viela trinitaria, bien que mediada, encarnada e historizadia.

Desde esta perspectiva. no sólo se ve mejor la unidad de la historia de Dios, sino que se ve lambièn mejor en qué consiste la dimensión lundamental clesde la cual ha cle pensarse el problema de la gracia y del pecado. Todo to creado es una forma limiracla de ser Dios y el hombre en concreto es un pe-

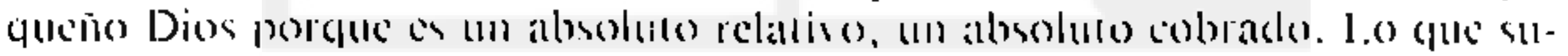
cede es que esa lorma limilada de ser Dios es en principio abierti. Esta aperlura ha de verse dinamicamente. pero ese dinamismo abierto no es olro que la presencia creciente de la realiclad divina en lo ereado. Cuando este dinamismo queda meramente limilado porque en un determinado nivel creatural no ha dado más de si, no puede hablarse iodavia de pecado, sino tall sólo de presencia deficiente de lo divino, aunque esa delïciencia no pucda medirse más que desde presencias más elevadas y menos deficientes. Pero cuando ese dinanismo cuecla limitado, ya no en la cvolución natural, sino en el proceso histórico - seia personal o social- por una negación deliberada, la cual al absolutizar el limite impide el dinamismo de la vida trimitaria e incluso la niega 
explicitamente, aunque no pueda destruirla, cstamos lormalmente ante el pecado.

Esta absolutización del limite en lo personal y en lo social tiene un doble aspecto: por un lado, impide que el 'más' de Dios se haga presente de nuevo, y esto constituiría el elemento privativo y no formalmente negativo del Dios que quiere hacerse más presente; por otro lado, absolutiza y diviniza un limite creado y en ese sentido niega positivamente a Dios y cae en la idolatria. En el pecado, aunque pucla parecer paradójico, hay una afirmación de Dios en cuamo el pecador se atiene a un bien que es presencia de Dios; pero hay sobre codo una megación de esa alirmacion, porque se pone como presencia plena y definitiva de Dios algo que no es sino presencia parcial y Iransitoria, negando así un 'más,' el cual es la presencia hisiórica de lo trascendente. Dicho de otro modo, la idolatría, como absolutización de lo limitado, cierra y niega lo que de presencia divina hay en lodo lo histórico. Es precisamente al celrarse en un limice lo que niega la presencia de ese 'más' y de ese 'nuevo,' a través de los cuales sc hace presente la trascendencia en forma de revelación personal. Se atribuye asi carácter divino a lo que no lo tiene en su limilación, porque se absolutiza un límite, pero esa atribución y esa absolutización son posibles sólo desde la presencia de lo divino, desde la dimensión teologal. Más que de ateismo hay que hablar entonces de idolatria, de absolutización absoluta de lo que ian sólo es relativamentc absoluto. Con lo cual la gracia se torna en pecado.

Esto que puede parecer tan abstracıo, es fácil de ejemplificarlo en la vida real y pastoral. Monseñor Romero en su carta pastoral Misión de la Iglesia en medio de la crisis del pais 44 donde busca desenmascarar las idolatrias de nuestra sociedad, expone desde esta perspectiva la idolatría que supone la absolutización de la riqueza y de la propiedad privada, la absolutización de la seguridad nacional y la absolutización de la organización. Es fácil de ver cómo en la riqueza y en el poder se dan aspectos que tienen que ver con la presencia de Dios, pero es claro que su absolutización histórica los convierte en idolos a los cuales se sacrifican todas las ol ras posibilidades lumanas. En el yo individual y en su libcrtad hay tambien una prescncia de algo que liene que ver muy directamente con el Dios que se hace presente y opcra en la historia, pero la absolutización del yo y de su libertad hasta convertirlos en idolos, es to que hace que la gracia se presente como pecado. E.n Ios aparatos institucionales y en las realizaciones objelivas se da lambién la polencia cle Dios que va logrando una historia unás humana y abieria mediante unas estlucturas, instifuciones y cuerpos sociales que abren más y más al hombre, tanto a los otros como a sí mismo, hacia si mismo y hacia lo que es mas que si mismo, pero su absolulización idolátrica hace del límite un obstáculo positivo y una negación de lo que es siempre mayor que cualquier realización objetiva y que cualquicr pretensión subjetiva.

Visıas así las cosas, es posible conceptuar la historia de Dios unilariamente como una historia de gracia y una historia de pecado. Hay mayor o menor presencia de la vida divina, de la gracia y hay privación unas veces y negacion de la gracia olras. 
3.4. El problema está, entonces, en discernir qué hay de gracia y qué hay de pecado en una determinada coyuntura histórica. Debe preguntarse con todo rígor cuál es hoy el pecado det mundo o en qué formas se presenta hoy el pecado del mundo, un pecado que es distinto de los pecados personales, muchas veces condicionado por aquél y a la vez sus continuadores y prolongadores. Aquí es clonde la leologia de la liberación situada en la entraña de la praxis pasiva y aciiva de los pobres ha dicho su palabra y ha sacudido la conciencia de la Iglesia y ell alguna forma también la conciencia del mundo.

En clecto. vista la realidad del mundo en su conjunto desde la perspectiva de la fe se juzga que el pecado del mundo se expresa hoy de forma punzante en lo que pucde Ilamarse la pobreza injusla. Pobreza e injusticia se presentan hoy como la gran negación de la voluntad de Dios y como la aniquilación de la presencia querida de Dios entre los hombres. Tanto la pobreza como la injusticia son Tenómenos empiricos, de cuya universalidad no habia querido percatarse el Primer Mundo, matriz de las teologias tradicionales. Sin perder su carácter cmpírico, que debe ser analızado con la ayuda de mediaciones cientificas, a la luz. de la fe aparece el mismo fenómeno, y no otro, como acontecimiento fundamental de la historia de Dios con los hombres. Los pobres y la pobreza injustamente infligida, las estructuras sociales, económicas y politicas que fundan su realidad, las complicadas ramificaciones en forma de hambre, enfermedad, cárcel, lorlura, asesinatos, etc., - realidades todas ellas tomadas muy en serio por la trascendencia histórica veterotestamentaria y por la neotestamentaria-, sin dejar de mostrar su carácter empírico van viéndose a la luz de Dios, tal como se revela en la escritura, en la tradición y también en la inspiración actual del Espírilu. Todo ello es la negación del reino de Dios y no puede pensarse en el anuncio sincero del reino de Dios dando la espalda a esa realidad o echando sobre ella un manto que cubra sus vergüenzas. No es menester insistir en este punto que ha sido subrayado primero por la experiencia de los creyentes, luego por el magisterio de la Iglesia, finalmente por la elaboración teológica de los expertos.

Correlativamente hay que responder qué hav de gracia en la actual coyunlura. Desde la perspectiva de la Iranscendencia cristiana, especialmente ıa neotestamentaria, se responde que por lo pronto los pobres, empobrecidos y oprimidos por la injuslicia, convierten en lugar preferido de la benevolencia y de la gracia, del amor fiel de Dios. Este empezar a ver las cosas preferencialmente desde ios poures es una de ias caracicrisucas esenciales ue la llatıxenuencia instórica cristiana: el anonadamiento que lleva a la exaltación, la munerte y muerte en cruz. que lleva a la resurrección, el padecimiento que lleva a la gloria, los más pequeños que son los más grandes en el reino, los pobres a los que se prometen las bienaventuranzas... todo esto es el modo histórico de hacerse presente el Dios de Jesús entre los hombres y en la marcha de la historia. Todos los nombrados son cignos especificamente cristianos que el Nuevo Testamento

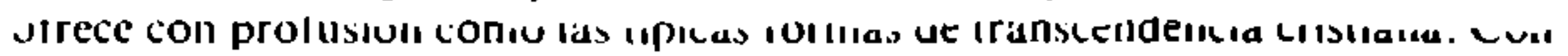
causa la teologia de la liberación ha repetido como uno de los textos fundamentales de su inspiración, las palabras veterotestamentarias que el evangelista ha puesto en boca de Jesús para mosirar el cumplimiento del Antiguo en el 
Nuevo Testamento: "Hoy, ante ustedes, se ha cumplido este pasaje" (L. 4, 21), el pasaje de Isaías que prometc bucnas nolicias a los pobres, libertad a los cautivos, vista a los ciegos, libertad a los oprimiclos (ls $61,1-2$ ).

Por eso, no se trata sólo de la existencia de los pobres y de la conciencia comada por ellos en la historia de la salvación, pumto tenido en basıante negligencia por la Iglesia a lo largo de los siglos. Se trata de su deseo de cue, en primer lugar, la Iglesia sc conforme al deseo de Jesús y, en segundo lugar. de su participación activa en que el anuncio del reino se vaya convirticnclo paulatina. mence en algo que pucda conslatarse históricancollc. I.os pobres han siclo evangelizados, han sido concicntizaclos y han decidido poner su lucrata crisiiana en favor de su liberación. Esio los lleva a veces a compromisos politicos, como supuestamente su inspiración cristiana llevaba, sin escánclalo, a los crislianos europeos a intervenir en politica con el claro apoyo, en ese caso, de las autoridades eclesiásticas. Con cierta connaturalidad cse compromiso politico es con los sectores revolucionarios, lo cual les pone en contacto con ideologías que pueden afectarles como alcclaron ideologias capilalistas a aquellos cristianos europeos y latinoamericanos. Pero no por eso laan sustituido, como si fueran equivalentes, la inspiración tolalizadora de su lie y la interpretación totalizadora de otras ideologias, antes al contrario han ido logrardo que esas ideologias se vayan abriendo en si mismas. en su aplicación y en su referencia a la fe cristiana.

Se acusa por ello a la teologia de la liberación de convertir a los pobres evangélicos en una clase social y a la lucha por la liberación en una lucha de clases. Con ello quedaria favorecido el marxismo y las tendencias anticapitalistas, punto que parece de capital importancia a la lglesia instilucionaliz.ada. La teologia de la liberación estaría asi, no sólo influida por el marxismo, sino en el fondo subordinada a él. I.a acusación es de todo pumto incorrecta, desde el punto de vista melodológico y desde el punto de visıa personal.

Desde el punto de vista metodológico por cuanto confunde la parte con el Iodo, lo subordinado con lo principal. Querer, por ejemplo, hablar de la teologia de la liberación de inspiración marxisla y tomar como ejemplo principal alguna de las obras de Jon Sobrino, como es el caso de Ratzinger (45) es un llamativo error metodológico. Podrá haber más o menos marxismo en otros teólogos, pero en la teologia de Sobrino su presencia es absolutamente marginal. Pero es que además en cl conjumlo de la teología de la liberación la prescn. cia del marxismo es siempre algo derivado y subordinado, y es, en segundo lugar, algo decreciente a lo largo de los años. Por otro lado, la imsistencia en los pobres, aunque pueda favorecer en algún caso la lucha revolucionaria, no hace de ellos una clase social y en su presentación más estricla rompe el esquema de clases sociales, montado sobre la propiedad de los medios de producción, para presentarse, en cuanto intepretación leológica, como algo que desborda por arriba y por abajo el esquema clel proletariado estrictamente tal. Desde este punto de vista, la teologia de la liberación representa a veces una luerte crítica desde dentro a lo que puede llegar a ser una teoria sociológica que no se contrasta históricamente con las diferencias de la realidad. 
Desde el punto de vista pastoral es menester distinguir la clara opeión preferencial por los pobres de las ulteriores opciones políticas que delerminados grupos sociales pueden lomar, una vez comprendida su obligación con las mayorias oprimidas. Hay aqui una graduación muy precisa: primero es querer desde la fe irabajar en favor cle los pobres y segundo elegir el modo mejor de hacerio. Aquello primero es una opción pusamente cristiana, lo cual requiere poco urabajo de mediación y un la cual se hace mas visible la tranceenctencia hislórica cristiana. l.o segundo puede subdividirse ch olras dos opciones secundarias: Irabajar en lavor de las mayorias oprimidlas clesde un pullo de vista me-

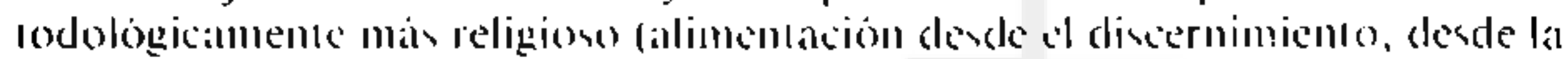
conversión, clc.) o desde un punto de vista más estrictamente politico (apoyoo afiliación a acjucllos grupos que de distinta forma quieren lievall adelante la causa de los más necesilados). Respecto de esta última opción, no es que la Iglesia no lenga nada que decir, pero criclentemente debe decirlo respetando la autonomia cle las instancias csirictamente politicas, sin dar por asentado que lavorecen más al reino de Dios y a las mayorias populares aquellas opciones politicas que respetan más las prelerencias y las necesidades de la lglesia instilucionalizada. Recordemos sólo de pasada cuánias veces ha considerado la Iglesia como algo conira la voluntad de Dios acciones que iban contra su poder remporal polílico o social, cuando en realidad eran acciones buenas en si y que luego han resultado de gran provecho para la Iglesia.

3.5. La Irauscendencia hisıcicica cristiana en su reasumpeion de la Iranscendencia histórica veterotestamentaria y neolestamentaria tiene un modo peculiar de relacionarse con el poder. Pareceria, en cfecto, que la tradición velerotestamentaria propenderia a ulilizar el poder de Dios en forma cle poder tstalal o cuasi estalal, mientras que la tradición neolestamentaria, siguiendo en esto lineas ya muy marcadas en el Antiguo Testamento. querria abandonar ese poder para alenerse más al poder sobre los individuos. En esla segunda lladición el poder religioso iria más a lo personal e interior, mientras que en la primera Iradición iria más a lo estruclural y público. Que no es asi del todo lo demuestra el empeño secular de la lglesia de afirmarse como un pocler institucional reveslido incluso de caracler estalal, en la linea de una sociedad perlecla, al modo como to son las sociedades estatales. Sill embargo, la iranscenden. cia histórica cristiana no repite ni el esquema personalista ni el esquema instiucionalista.

Electivamente pueden esquematizarse tres modelos hisıbricos, cada uno de los cuales admile diversas varianles.

Hay un primer intento de salvar a Isracl a lravés slel poder, pero de un poder concebido teocráticamente. Se busca que Dios salve al pueblo y salve a la historia como lo hacen los reyes y señores de este mundo, aunque se purifique ese modo puramente secular de hacerlo. Modelos de este intento son el propio Moisés, los jueces, los reyes, los macabeos, clc. Este intento tiene de fundamentalmente verdadero un elemento esencial: Dios quicre una salvación histórica, una salvación integral que tenga en cuenta el estado tolal de los hombres y de los pueblos, de modo que la salvación no se reduzca a algo espiritual o algo trans-temporal. Pero tiene otro elemento que se va a ir mostrando como ca- 
duco e incluso antisalvifico; ese clemento se esconde tras la persuasion cle cque la salvación ha de venir desde el poder — poder bélico, económico, polílico. religioso, incluso poder milagroso- - esto es, de un poder configeurado segúul tos poderes de este inundo por más que se los revista de ull carácter sagrado que los constiluya en poder leocrático.

Ante el fracaso repelido de este intento, aparece históricamente otro de características opuestas: el camino del poder no solo lleva cl liacaso histórico! al triunto del mal, sino que imposibilita el camino de la salvación. L.o que debe hacerse, por tanto, es abandonar el inundo a los poderes del mal y buxcar lia salvación y la santidad en la separación de cste munde. Asi xemerecera : ee logrará algún dia, al rinal de 'estos liempos,' que Dios irrumpá en la hisioria aplastando a sus enemigos, desterrando definitivamente el pecaclo y hacicuclo un nuevo mundo para los hijos de Dios. En esle intento, lo fundamentalmente verdadero es la afirmación de que la salvación de Dios supera y transciende la estructura y las posibilidades de lo estrictamente politico: la a firmación. por otra parte, de que lo politico, por muy necesario que sea, nunca podrá aportar la salvación integral que necesita el hombre. Pero tiene otro elemento que in. valida esta solución y es que la salvación no es algo que clebe operar y ser presente históricamente en las siluaciones reales de los hombres, de suerte quic étas vayan siendo paulatinamente Irans Tormadas hasta irse acercando a ser presencia real, aunque no definitiva, del reino de Dios. Ciertanente, hasta los esenios parecen reconocer la necesidad de una salvación hislórica, pues esperan y' aun anticipan de distintas formas una presencia nueva de Dios, una irrupción triunfante de Dios sobre el pecado de este mundo; pero no hacen histórica esa espera y esa anticipación dejando para más tarde esa presencia salvilica de Dios entre los hombres y entre las cosas de los hombres. Fallan, enionces, tanto en lo que tiene de positivo el 'todavia no' como en lo que tiene de positivo el 'ya,' aunque señalan con mucha fuerza la verdad del 'lodavia no' y la limitación histórica del 'ya.' En esta misma línea deben considerarse los que csperan la salvación sólo en el otro mundo reduciéndola en ésle a dimensiones puramente interiores o morales, dando una autonomia tal al mundo que lo separan de la historia de Dios y que lo dejan a merced de quienes son sus dominantes, salvo en el caso que estos dominantes limiten las riquezas y el poder de quienes se dicen buscar a Dios.

El tercer intento es el que marcaría mcjor la transcendencia histórica cristiana y buscaria salvar la historia haciendo presente en ella el poder cle Dios. pero el poder de Dios lal como se revela en Jcsús y del modo como se revcla en él. Esta presencia es una presencia verdaderamente hislórica, que opera rcalmente en la historia y busca su transformacion, pero ticne un modo peculiar de hacerlo que no es ni el retiro espiritualista de ella ni asume tampoco las formas del poder teocrático que fácilmente se convierte en poder idolatrizado. Concretiza históricamente las figuras clásicas de Moisés, del Mesias, del rey de los judios. etc., en la figura del siervo histórico de Yahvé no para retucirla a ser el protagonista de una expiación cultual de los pecados y de una impetración de la gracia, sino para darle cuerpo histórico a través de su palabra y de su accion. Superaría con ello los dos intentos anteriores, asumiendo lo que tienen 
de verdadero y fundamental, pero abandonando y negando sus puntos ambiguos y ralsificadores. Quc Jesús no buscó el poder teocrático es claro tras la lectura del Nuevo Testamento; que no se reliró del campo socio-histórico es también claro, si atendemos tanto a su vida como a su muerte. Su modo peculiar de intervenir historicamente, de hacer hislóricamente presente a Dios entre los hombres es, descle luego, anunciando el reino de Dios, haciéndolo presente en si mismo y poniéndolo en marcha; este anuncio y esta puesta en marcha del reino lleva como uno de sus elementos esenciales el comprometer la causa de Dios con la causa del hombre y, más concrelamenie, el comprometer la causa de Dion conl la causia del pobre. Será Dios en los pobres el que salvará la hisıoria, pero en unos pobres reales que realmente operarán sobre ella, cuando manicniendo su condición malerial de pobreza recuperan en ella la bienavenuranza lotal del don de Dios.

Es ell esta linea donde debe buscarse la peculiar de la 1ranscendencia histórica cristiana. Esta transcendencia presenta su novedad como ruptura con aquello que el mundo ha entendido como 'gloria' de Dios, como su presencia verdadera. Esa 'gloria' que ya aparece de algún modo en la grandiosidad de la naturaleza material como el poder de la majestad divina, la han puesto los hombres en distintos factores históricos, tales como la sabiduria humana, el milagro leocrático, la ley religiosa, la riqueza y el poder de la institución eclesiástica. Pero estos carnınos han dernostrado que no son apertura a la transcendencia, tal como ésta se nos revela en Jesús, sino que inmedialamente se convierten en límites absolutizados'y, en consecuencia, se constituyen en negación de Dios como pecado y cerrazón a la gracia. Al contrario, Jesús ha desechado lo que es grande para los hombres y ha tomado como sacramento de Dios lo que es despreciable para los poderosos de este mundo. Esta grandeza admirada y es pequeñez despreciable pueden tomar distintas figuras históricas, pero siempre ofrecen una constante historica: la de privilegiar al rico y poderoso y la de dominar y explotar al que no tiene sino pobreza y debilidad. Por eso, frente a los falsos caminos de la transcendencia hisiórica cristiana, hay que abrir por lo pronto el camino de la negación, esto es, la negación de los falsos caminos hacia Dios, de los falsos dioses y de los falsos mesianismos. Hay también que propiciar positivamente los verdaderos y cristianos caminos de Dios. $\mathrm{Y}$ estos son, en contradicción con los anteriores: la fe cristiana frente a la sabiduria del mundo, el poder del crucificado frente al milagro teocrático, la gracia y el amor frenle a la ley religiosa, la pobreza y el servicio frente a la riqueza y el poder. Todo ello se reduce al mandamiento del amor, sólo que de un amor entendido cristianamente e historizado adecuadamente.

Ahora bien, todo esto opera en la historia. Por eso tanto la negación como la afirmación deben tomar carne en la historia. Y la prueba de que lo están haciendo no puede ser otra que la de la persecución. Lo que para los griegos ега locura y para los judios escándalo, para los que viven del pecado se les convierte en amenaza y por eso responden con persecución. La persecución por causa del rejno es prueba rehaciente de dos cosas fundamentales en la praxis histórica de la salvación: que la salvación anunciada se está haciendo presente históricamente; de lo contrario no habría persecución histórica, y que la salva- 
ción anunciada es real y rerdaderamente crisliana, pues de lo contrario no seria contradicha y perseguida por quienes representan y objelivan los valores anticristianos.

El problema no está entonces en que no debe ponerse el podet de Dios me. diado por los hombres en la mejora de las realidades históricas, sino en ponerlo como Dios quiere. Y cómo lo quicre Dios lo sabemos primariamente en Jesús, una vez que haya podido inedirse cual es la siluacion concrea en la cual se ha de actuar, en Jestus que aclualiak su mensaje de distintas lormas y por distintos canales, pero que siguc siendo el criterio fundamental con el cual comtrastar en nombre de Jesils.

3.6. Hasta ahora se hatn resaltado acui algumos aspeces objecivos de la

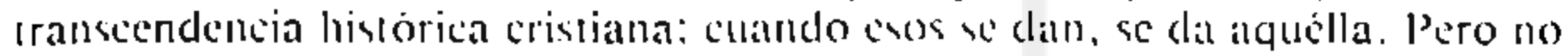
hemos insistido sulicientemence en lo que pudiera llamarse el encuentu perional de esa transcendencia hisiórica crisuiana. Es, en clelinitiva, el problema cle la espiritualidad de la teologia de la liberación, que cada día va cobrando mayor imporlancia entre los lcóloges latinoamericanos, injuslamente acusados de secularistas y politizados. ${ }^{46}$

Gustavo Guliérrez ha enfocado inicialmente csle tema desde la célebre concepción de raigambre ignaciana del "contemplativo en la acción." La acción representaria el elemento objelivo y la contemplación el elemento subjetivo: sólo cuando se alcanzara la debida contemplación en la acción debida estariamos en el verdadero camino de realizar y asumir la transcendencia hisı́́rica cristiana.

El problema, por lo pronto, esıá en determinar cuál es la acción o el proyecto fundamental de acción en el cual se da con mayor plenitud la transcendencia histórica cristiana. Pues bien, desde un punto de vista lalinoamericano $y$, en general, terccrmundista, esa acción es fundanentalmente una acción liberadora de todo aquello que impide que el reino de Dios se haga presente entre los hombres, de todo aquello que impide que Dios se muestre como un poder de vida y no como un poder de muerle. Supone esto ver como el mayor problema del mundo y el mayor pecado del mundo aquella situación universal y estructural que hace que la inayor parte de la humanidad viva en condiciones que el propio Santo Tomás estimaria como prácticamente imposibilitadoras de llevar una vida humana regida por principios morales, situación debida a la culpabilidad objetiva - sea pecado de comisión o de omisión- de unas minorias dominantes las cuales han hecho de la dominación, de la explotación. del consumismo, los dioses de su existencia institucional. En este proyecto fundamental de acción es clonde se da actualmente la máxima posibilidad de manirestación objetiva de la volunıad y de la presencia del Dios de Jesús. No es éste el único pecado que hay en el mundo, pero es la malriz. Pundamental de muchos olros pecados, en relación a la cual hay que medirlos. Combatir este pecado histórico, cuya objetivación puede ser seguida con facilidad; superarlo para que dé paso a una nueva situación, es el desafio fundamental de la misión cristiana en su anuncio y realización del reino, si tomamos el problema a escala mundial. Ese pecado es la negación de la paternidad divina, de la fraternidad 
humana descubicra ell el Hijo y del amor que el Espiritu ha derramado sobre lodo el mundo; esc pecado és la negación del hombre en sus derechos más lundansentales: ese pecado es origen de violencias. conflicıs y divisiones: ese pecado oblura los caminos de Dios hacia el hombre y del hombre hacia Dios.

Se trala, por otra parte, de una liberación universal. Desde luego de una liberación inlegral que no se quede en problemas exclusivamente económicos o politicos, pero también de una liberación universal. Hay que liberar al pobre de su pobreza, pero hay que liberar también al rico de su riqueza; hay que liberar al oprimido de su ser dominado y hay que liberar al opresor de su ser domi-

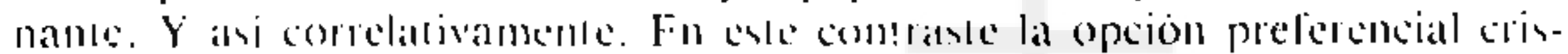
liana, sin negar su universalidad. está clara: ce en lavor del pobre, del oprimido.

Perosi se quiere cyuesta liberación sea real. esto es, que el pecado no sólo se perdone sino que se quite, habrá que echar mano de mediaciones no sólo analiticas, sino también prácticas. Es aqui y sólo aqui donde surge en la teologia de la liberación la necesidad de recurrir al análisis marxista y, en su caso, a praxis que pudieran considerarse como marxistas. No vamos a entrar en la discusión de este punto. Todas las páginas anteriores muestran hasta qué punto puede presentarse el problema de la transcendencia hislórica sin hacer referencia al marxismo y sin lener que someter las ideas cristianas a ideologias marxisıas. Pero sí conviene seỉalar que cuando la teologia de la liberación pide ayuda conceptual al marxismo, no sonele su discurso al discurso marxisıa, sino al revés; intenta asi con mejor o peor fortuna lo que cualquier otra teologia ha hecho con ot ras 'iclcologias,' a veces con escándalo del magisterio y a veces con tácilas aprobaciones jerárquicas, al menos Iras un tiempo de recelo, a saber, potenciar su discurso teológico con aquellos elementos que no cierran la Iranscendencia, sino que la posibilitan.

Si esta es la acción fundamental en la cual se ha de ser contemplativo hay que preguntarse breventente por las caracteristicas cristianas de esta contemplación. El pumto fundamental viene dado por la acción, porque intentar contemplar a Dios Jonde Dios no quiere darse a contemplar o donde efectivamente no está. pues el limile ha sido absolutizado. es un error subjetivista. La parábola del samaritano ( Lc 10, 25-37) deja en este punto las cosas bien claras: el verdadero prójimo no es ni el sacerdote ni el levita que pasan de largo ante el Jolor del marginado y malherido, sino cl samaritano que carga con él y le proporciona cuidado malcrial, resolviéndole asi su situación en la cual injustamente se habia visto involucrado. Esta acción aparentemente profana, aparentemente natural. anaremtemente desconocedora de su significado es mucho más Iranscendente y cristiana que lodas las oraciones y sacrificios que pudieran hacer los sacerdoles de espaldas al dolor y a las angustias de su medio circundante. Pero es que, además, la conternplación puede y debe someterse a mucho examen para saber si es cosa de Dios o cosa idolátrica. Hay peligros en la acción, pero no los hay menos en la contemplación. Desde el "no quien dice Senoor, sino el que hace la voluntad del Padre," pasando por tantas ot ras advertencias neotestamentarias y veterotestamentarias, especialmente las de Juan que unifica la luz (contemplativa) con la acción de amor y las tinieblas (oscure- 
cedoras de Dios) con la acción de odio o desamor ( $1 \mathrm{Jn}$ 1, 5 ss) hasla llegar a los maestros de la contemplación, nos encontramos con una serie de advertencias, los cuales ponen muy en guardia contra algunos tipos de contemplación que desvian su mirada y su propósito de la acción en la cual Dios se quicre hacer realmente presente.

Pero una vez identificada la acción debida, tanio en lo que es el proyecto general de vida cristiana como en sus diversificaciones particulares, hay que tratar de ver algunas notas propias de la contemplación misma. El contemplativo en la acción debe ser realmente contemplativo, debe intentar encontrar subjetivamente a Dios en lo que objetivamente cstà realizando. Podrá haber cristianos anónimos, podrá haber experiencias atemáticas de Dios. pero ése no es el ideal, sino que es deseable que la objetividad más rica se convierta en la subjetividad más plena.

Esa contemplación debe ser desde el lugar más adecuado. El 'desde donde' en el cual se sitúa uno al querer ver, es decisivo para lo que se puede alcanzar a ver; el horizonte y la luz que se seleccionen son también fundamentales para lo que se va a ver y el modo como se va a ver. Pues bien, el lugar desde donde la luz con que y el horizonte en el cual se quiere encontrar a Dios es desde luego Dios mismo, pero Dios mediado en ese lugar singularmente elegido por él que son los pobres de la tierra. Esta mediación de los pobres no limila, sino que potencia la fuerza de Dios lal como se puede presentar en la escritura, en la tradición, en el magisterio, en los signos de los tiempos, en la propia naturaleza, en la marcha de la historia, etc. La contemplación descansa sobre una espiritualidad de la pobreza; asi podria inlerprelarse la pobreza de espiritu, un saber vivir con espiritu la pobreza y la identificación con la causa de los pobres, entendida como causa de Dios: Desde esa perspectiva de los pobres se ven nuevos sentidos y nuevas incitaciones en el legado clásico de la le. Como es tarea que apenas se ha hecho a lo largo de la hisloria, al menos en el nivel de la reflexión teológica, aparecen novedades que habian pasado inadvertidas para quienes se habian situado en las grandes monlañas para avizorar mejor el horizonte de Dios. Contemplan más y mejor aquellos a los que Dios ha querido revelarse más: "bendito seas, Padre, Señor del cielo y tierra, porque, si has ocultado estas cosas a los sabios y entendidos, se las ha revelado a la gente sencilla. $\mathrm{Si}$, Padre, bendito seas, por haberte parecido eso bien. Mi padre me lo ha enseñado todo; quién es el Hijo lo sabe sólo el Padre; quièn es el Padre lo sabe sólo el Hijo y aquel a quien el Hijo se lo quiera revelar" (Lc 10, 21-22). El texto ofrece diversas lecturas posibles, ${ }^{47}$ pero una de ellas es de aplicación a lo que sería condición indispensable para ta contemplación cristiana de la transcendencia histórica de Dios, para la captación de lo que hay de Dios en la hisıoria.

Es un prejuicio confundir el grado de contemplación porque to contemplado sea en apariencia más o menos sagrado, más o menos interior, más o menos espiritual. Se supone asi que Dios estaria más presente, audible o contemplable en el silencio interior del ocio que en el compromiso de la acción. Esto puede que no sea asi y no tiene por qué ser asi. Puede ser que en el camino de Emaús se encuentre a quien se está buscando en el pasado, en el recuerdo de acciones sagradas o que en el camino de Damasco se rompa una religiosidad 
falsa y farisaica en favor de una contemplación y conversión cualitativamente incomparables con tas del estado anterior. No es seguro que la iranscendencia cristiana se encuentre mejor en el templo que en la ciudad, y menos aún en la preocupación por sí mismo, en lugar de en la preocupación por los demás. Por otro lado, una praxis realmente cristiana, que busca desde los más necesitados, el camino para la anulación del gran pecado del mundo y para la implantación de la vida divina en el corazón de los hombres y en el núcleo de las estructuras, Irae consigo enormes riquezas por la urgencia y profundidad de las demandas, por la experiencia compartida, por la comunicación de lo que se tiene, que son ellas mismas hendicluras a través de las cuales se llega más rápicla y profundamente al Espíritu de Cristo que anima a su pueblo.

Todo ello no obsla a que deba subrayarse muy enérgicamente que hace falta contemplación y que la conlemplación exige unas condiciones, cuyo olvido deja a la posibilidad de descubrimiento de la acción verdadera en un grado muy bajo. Entre esas condiciones no pueden olvidarse las de indole explícitamente revelante; querer sacar de la praxis, por muy correcta que sea, lo que Dios quiere decir al hombre, no sólo es erróneo, sino herético, porque aunque Dios habla y ha hablado "en múltiples ocasiones y de muchas formas" (Hb 1, 1), nos ha hablado definitivamente por el Hijo; en esta misma línea hay que situar toda la revelación y en su caso la tradlción. Tampoco pueden olvidarse las condiciones de vida personal, porque aunque Dios puede manifestarse al más pecador, no hay duda que lo normal es que esa manifestación comience por la conversión y la purificación: son los limpios de corazón los que mejor verán a Dios (Lc 5,8). Y tampoco pueden descuidarse las debidas condiciones psicológicas y metodológicas; aunque la inmersión en la acción posibilita riquezas enormes de realidad, se requiere de momentos especiales para que se pueda recoger y protundizar conscientemente el entrechoque de la palabra de Dios que se escucha en la revelación con los problemas urgentes que suscita la realidad en la mediación de la propia mismidad.

El contemplativo en la acción puede significar tan sólo aquella contemplación que se puede y se debe tener mientras se actúa. Aqui se le da un significado más amplio, el cual no se reduce tampoco a contemplar lo actuado, sino a hacer de lo actuado o de lo por actuar algo que pueda llamarse estrictarnente contemplación, encuentro de lo que hay de Dios en las cosas y encuentro de Dios mismo en las cosas. No hay, pues, aqui una puerta abierta al activismo o un abandono de todo retiro espiritual ni menos de toda celebración litúrgica. Al contrario, se busca explicitar en la palabra, en la comunicación, en la vivencia, lo que de manera menos explícita se ha encontrado en la accion. Y sabe mos que se ha encontrado en la acción, primero porque así lo ha prometido lesús en el caso de un compromiso cristiano con los más necesitados y, segundo, porque en el discernimiento de la contemplación se contrasta lo que es de Dios y lo que es contra Dios. Así, por ejemplo, cuando la celebración de la palabra, las reuniones penitenciales o las eucaristias han sido cargadas de todo lo que se exige personal y comunitariamente al trabajo del que en ellas participa (opus operantis), es cuando su propia gratuita efectividad (opus operatum) se da y se recibe en plenitud. Hay, pues, en esta contemplacion un esfuerzo por actuali- 
zar lo que ya está presente: es esto ya presente el principio fundamental de la actualización, pero necesita de una subjetividad preparada para que se cumpla de modo mejor la actualización.

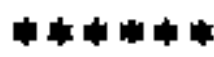

Finalizamos aqui el esquema de lo que deberia ser un tramiento de la transcendencia histórica cristiana. Otros temas deberían ser tratados, especialmente el de la lglesia como forma privilegiada de mostrar la transcendencia histórica cristiana, ${ }^{48}$ y los temas aqui apuntados deben ser analizados con mayor rigor. Pero lo que se prelendia era mostrar la importancia del problema y algunos elementos para su solución o, al menos, para una ulterior discusión. Pannenbery escribia: "Geschichte ist der umfossendste Horizont christlicher Tehologie. "49 Del artículo en que se encuentra esa frase se desprende que para él no sólo la teologia, sino la revelación misma encuentra en la historia su horizonte más globalizador. Efectivamente es así. Una historia que abarca tanto la historicidad de las existencias personales como la hisloria real de los acontecimientos empiricos; una historia que no es ni Ur-geschichte ni Uebergeschichte, pero que es, en su mismo carácler empirico, transcendente, esıo es, abierla a Dios porque en ella Dios se ha hecho primero presente.

La transcendencia histórica no es entonces un tema exclusivo de la teologia de la liberación, pero ésta tiene un modo propio de entender lo que es formalmente una transcendencia histórica cristiana. En las páginas que preceden se ha procurado indicar algunas formas de expresar ese modo propio. Con ello, se ha querido señalar la peculiaridad y la universalidad de la teología de la liberación y, al mismo tiempo, su novedad y su tradicionalidad. No se ha expuesto lo que los teólogos de la liberación han pensado sobre este punto; se ha pretendido tan sólo mostrar una de las formas posibles de conceptualizar el problema. Sobre él hay todavia mucho que trabajar desde estudios bíblicos, hermenéuticos, dogmáticos y pastorales. Pero la teología de la liberación muestra Iodavia tal vitalidad que es de esperar que esos Irabajos se vayan realizando.

\section{NOTAS BIBLIOGAAFICAS}

1. Alfaro, J.. Esperanza cristiona y liberacion del hombre, Barcelona, 1972.

Alonso J. y otros, Fe y justicia, Salamanca, 198]

Bultmann, R.. Geschichte urd Eschatologie. Tubingen, 1970.

Cullmann. O., La historio de ta sahracirin. Bartelona, 1\%67.

Darlap, A., "Teologia fundamental de la historia de la salvación," en Mysterimm Salutis, I, 1, Madrid, 1969, 49-204, con bibliografia.

Me1z, J. B., Teologia del mundo Salamanca, 1970.

Moltmann. J., Teología de la esperanza. Salamanca, 1977.

Molimann, J., Umkehr zur Zukumf. München, 1970.

Pannenberg, W., Grundfragen sustematischer Tehologie, Gouingen, 1967.

Rahner, K., Horer des Worles. München, 1963.

Rahner, K., "Weltgesehichte und Heilsgeschichte," en Schrifien zur Theologie, V, Einsiedeln, 1962, $115-135$.

Robinson, J. M. y Cobb, J. B., Theologie als Geschichte , Sttulgarl, 1967.

Solle, D., Teologia politica. Salamanca, 1972. 
2. Alves. R.A., Cristianismo, ¿opio o liberación? Salamanca. 1973.

Assman. H., Teología desde la praxis de la liberación. Salamanca, 1973.

Bolf, Cl., Teologia de lo politico, Salamanca, 1980.

Boff. L.. Jesucristo y la hiberación del hombre. Madrid, 1981.

Boff,L., Teologia del cautiverio y de la liberacion. Madrid, 1978

Comblin, J., Theologie de la pratique révolutionnaire. Paris, 1974

Dussel, E.D., Histoire et theologie de la liberation. Puris, 1974

Ellacuria, l.. Teologia Dolíica. San Salvador, 1973.

Ellacuría, l., "Tesis sobre la posibilidad, necesidad y sentido de una teologia lattinoamericania."

en Varios, Teología y munto coniemponineo. Madrid, 1975, 325-350.

Ellacuria, I., "Fe y Justicia," en Varios, Fe, Justicia y opcion por los opmimirles, Bilboro. $1980,11-78$.

Ellacuría, l., "El pueblo crucificado. Ensayo de una soreriologia hislórica," enl Varios, (ru: y resurrección. 1978, 49-82.

Gutietrez, G., Teologia de la liberacion. Salananca, 1977.

Gutiérrez G. Teología desde el reverso de la hislorio, Lima, 1977.

Gutiérrez, G. Beber en su propio pozo. Lima, 1983.

Instituto Fe y Secularidad, Fe cristiana y cambio social en America Larina, Salamanca 1973.

L.ibanio, J.B., Discernimento e Pollica. Petrópolis, 1977.

Scannone, J.C., Teologia de la liberación y praxis popular, Salamanca. 1976.

Segundo, J.L., Liberación de la teología. Buenos Aires, 1970.

Segundo, J.L., El hombre de hov ante Jesús de Nazaret, Madrid, 1982.

Sobrino, J., Cristología desde América Latina, México 1976

Sobrino, J., Jesús en America Latina. San Salvador, 1982

Sobrino. J., Resurrección de la verdadera Iglesia. Saniander. 1981.

Trujillo, A.L., Liberación marxisia y liberación cristiana. Madrid, 1974.

Varios, Lo esperanza en el presente de America Latina. San Jose, 1983.

Zwiefelhofer, Bericht zur "Theologie der Befreiling." München, 1974.

3. Vaticano II, Constirucion "Gaudium el Spes," 1965. CELAM, Doctmemtos de Medellin, 1969. Pablo VI, Evangelii nuntiandi, 1975. CELAM, Phiebla, 1979. Conscjo Permanente Episcopado de Francia. Libérations des hommes et salut en Jésus Christ. 1974.

4. Comisión teológica internacional, Teología de la liberación. Madrid 1978, IAI.

5. von Balthasar, H.U.. "Reflexiones histórico-salvificas sobre la tcologia de la liberación" en CTI, Teología de la liberación, 1 . c., 181.

6. Ratzinger, J., "Vi spiego la teologia," 30 Giorni marzo, 1984, 49.

7. ib.

B. Boff, Cl., 1. c.

9. ib., $27-29$ y passim.

10. Obispos y superiores religiosos del Nordeste, Eu ouvi os clamores de meu novo, Salvador, 1973.

11. Cfr. Zubiri, X., Sobre ta esencia, Madrid, 1962; Inteligencia sentiente, Madrid, 1980; /mleligencia y logos, Madrid, 1982; Inteligencia y razón. Madrid, 1983.

12. I. c., 170 .

13. Chenu, M.D., "Les signes des lemps," Nouvelle Revue Theologique, enero. 1965. McGrath, M. " "Los signos de los tiempos en América Latina hoy," en Los texas de Medellín. San Salvador, 1977, 137-158.

14. Colins, J.J., "The 'historical" character of the Old Testament in rccent biblical theology." The Catholic Biblical Quaterly, April, 1979, 185.204.

15. Kritik der praktischen Vernunfl, Hamburg. 1929, 288-292.

16. North, M., Esodo. Brescia, 1977. 11.

17. de Vaux, R., Histoire ancienne d'/sroel, Paris, 1971, 305 ss.

18. ib., 310.

19. Ex 20,2 y 39,46 ; Lev 19,36 y 25,$38 ;$ Di 5,6

20. $\operatorname{Ex} 7,13,22 ; 8,15 ; 9,35$.

21. Ex 9,12; 10,20,27.

22. Ex 7,$14 ; 9,34$ y 10,1 .

23. North. M., I.c., 167 
24. von Balthasar, H. U., I.c.. 167

25. de Vaux, R., 1. c.., 306 ss.

26. CTI. I.c., 192.

27. Cfr. comentarios biblicos sobre el sermón de la montina, sobrc la nueva ley: mas precisamente los comentarios sobre Hb 3. I-6.

28. Boismard, M. E. y l.amunille,A., L'Evamg/e de Jcum. Paris, 1977. 9.70.

29. Jaris y oletheia más que gracia y verdad significan amor y lïdelidad. donde lidelidad os un

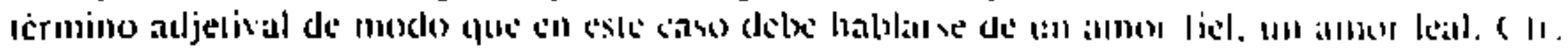

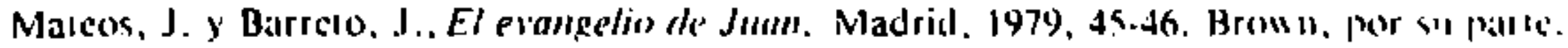
Iraduce iambién arnor consıante: cfr. Brown. R. E... Fleranedio segum. Jum. Maclricl. 1979. 1, IR9-190.

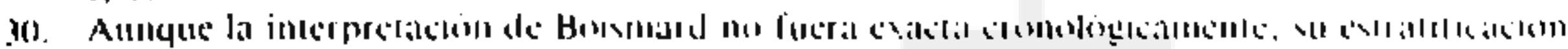

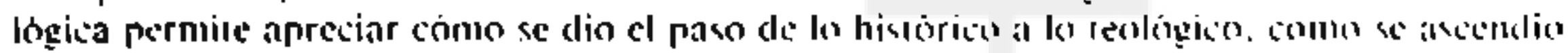

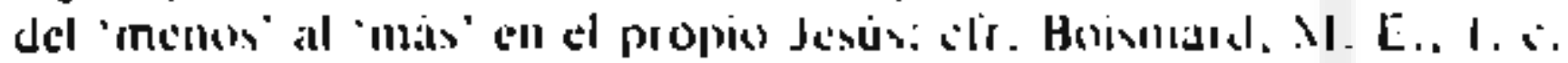

31. Boismard, I.c.. 95.

32. ib., 104.

33. Cullnam, 0., 1.c... 320 .

34. Rahner, K., 1. c.

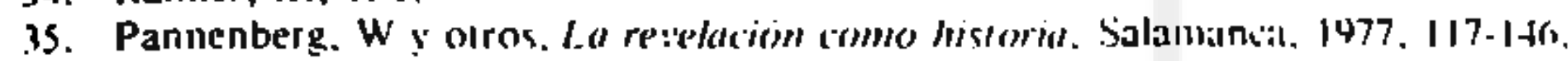

36. Popol Vuh. Las amighas tradiciomes historicas del tumchi. San Salvador. 1980.

17. Cabarrus, C. R., La cosmovisión k'ekchi' en mroceso de cumbio. San Salvador. 1979.

38. Boff, Cl., 31-144.

39. ib., 135-285.

40. 1.c. 179 .

41. ib.

42. Zubisi ha visto la necesidad de reconocer un pecado histórico, además de un necado personal y un pecado original; cfr. Zubiri, X., Narturoleza, Historia, Dios. Madrid, 1963. P. 394.

43. Sobre esios punlos podrá leerse pronto el libro póstunio de Zubiri, El hombre y Dirs.s.

44. clr. Sobrino, J., Marrin-Baró, I. y Cardenal. R., La roz de los sin ros. San Salvador 19An. 123-172; sobre las idolatrias, 145-149.

45. 1. c.. passim

46. cfr. Gutièrrez, G., Beber en su propio pozo, Lima, 1983: Sohrino, J., "Espirilualidad y liberación, "Diakonia. junio. 1984, 133-157; Ellacuris, 1. "Espiritualidad" en Filoristàn. C. y Tamayo, J. J. (ed.), Concepios fundomentales de pas/oral, Madrid, 1983, 301 -309. donde se da bibliografia.

47. cfr. Boisnard. 1. c., 169-170.

48. Uno de los lugares en donde a modo de ejemplo práclico pucde vislumbrarse este problema es en Iorno al problema de las organizaciones populares en EI Salvador, lal como se reneja en Ia publicación Iglesia de los pohres y organizaciomes populares. San Salvador. 1979. Аyui xo analiza una Carta Pastoral de Monseñor Romero y Monsentor Rivera sohre cute problema. En general, se podia apelar aqui a toda la hibliografía sobre la Iglesia de los nobres.

49. Pannenberg W., Grundfragen systemarischer Theologie. Güningen, 1967, 22. 